\title{
Retrieval of snow grain size and albedo of western Himalayan snow cover using satellite data
}

\author{
H. S. Negi ${ }^{1,2}$ and A. Kokhanovsky ${ }^{2}$ \\ ${ }^{1}$ Snow \& Avalanche Study Establishment, Him Parisar, Sector-37A, Chandigarh 160 036, India \\ ${ }^{2}$ Institute of Environmental Physics, University of Bremen, O. Hahn Allee 1, 28359 Bremen, Germany \\ Received: 5 December 2010 - Published in The Cryosphere Discuss.: 16 February 2011 \\ Revised: 4 August 2011 - Accepted: 22 September 2011 - Published: 14 October 2011
}

\begin{abstract}
In the present study we describe the retrievals of snow grain size and spectral albedo (plane and spherical albedo) for western Himalayan snow cover using Hyperion sensor data. The asymptotic radiative transfer (ART) theory was explored for the snow retrievals. To make the methodology operational only five spectral bands $(440,500,1050$, 1240 and $1650 \mathrm{~nm}$ ) of Hyperion were used for snow parameters retrieval. The bi-spectral method $(440 \mathrm{~nm}$ in the visible and $1050 / 1240 \mathrm{~nm}$ in the NIR region) was used to retrieve snow grain size. Spectral albedos were retrieved using satellite reflectances and estimated grain size. A good agreement was observed between retrieved snow parameters and ground observed snow-meteorological conditions. The satellite retrieved grain sizes were compared with field spectroradiometer retrieved grain sizes and close results were found for lower Himalayan snow. The wavelength $1240 \mathrm{~nm}$ was found to be more suitable compared to $1050 \mathrm{~nm}$ for grain size retrieval along the steep slopes. The methodology was able to retrieve the spatial variations in snow parameters in different parts of western Himalaya which are due to snow climatic and terrain conditions of Himalaya. This methodology is of importance for operational snow cover and glacier monitoring in Himalayan region using space-borne and airborne sensors.
\end{abstract}

\section{Introduction}

Snow in Himalaya is an important natural resource. It is a potential source for major rivers, melt-runoff, regional climate and snow avalanches. Monitoring of vast snow cover areas of Himalaya using field based survey is difficult due to harsh weather conditions, time consuming, provide lim-

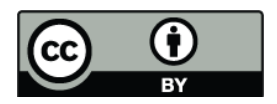

Correspondence to: $\mathrm{H}$. S. Negi

(hs.negi@sase.drdo.in) ited region information and hazardous. Now with the use of remote sensing techniques, snow cover information can be determined on real-time, year-round, over vast, rugged and remote areas (Konig et al., 2001). Numerous studies have been performed on the mapping of seasonal snow cover using different methods and optical sensors globally (Dozier et al., 1981; Dozier 1984, 1989; Hall et al., 1995, 2002; Klein et al., 1998; Vikhamar and Solberg, 2003; Salomonson and Appel, 2004; Painter et al., 2009). In addition, many studies have been conducted on snow cover mapping in Himalaya using optical satellite sensors (Gupta et al., 2005; Kulkarni et al., 2006, 2010, 2011; Jain et al., 2008; Negi et al., 2009a; Immerzeel et al., 2009). Apart from mapping, monitoring of snow properties such as snow grain size, albedo, snow pollution (contamination by soot, soil, etc.), snow surface temperature, moisture, etc. are important for many applications. Now with the advent of many new improved spectral, spatial and radiometric sensors (Table 1), it is possible to retrieve quantitatively the snow characteristics such as fractional snow cover, grain size, albedo, snow surface temperature, etc. Several studies have been reported on retrieving snow grain size and albedo using various techniques for different areas, as discussed in the following sections. But due to the complex topography of Himalaya and limited access to high mountains for field investigations, only qualitative or empirical relation work have been reported for snow properties.

\subsection{Remote sensing of snow grain size}

Retrieval of snow grain size from Landsat Thematic Mapper (TM) data at $30 \mathrm{~m}$ spatial resolution has been discussed in previous studies reported in the literature. Dozier (1989) has retrieved snow grain size using TM band-4 $(0.85 \mu \mathrm{m})$ data, and reported qualitative results of snow grain size for Alpine snow cover. Nolin and Dozier (1993) estimated snow grain size using Airborne Visible/Infrared Imaging Spectrometer

Published by Copernicus Publications on behalf of the European Geosciences Union. 
Table 1. The major currently operating optical imaging earth observation satellite instruments suitable for snow cover study.

\begin{tabular}{llll}
\hline Satellite & Sensor & Spatial resolution and spectral bands & Agency \\
\hline Landsat-7 & ETM+ & $30 \mathrm{~m}$ (Vis-SWIR), 60 m (TIR); 8 bands & NASA, \\
Terra & ASTER & $15 \mathrm{~m}$ (VNIR), 30 (SWIR), 90 m (TIR); 14 bands & USGS \\
Terra/Aqua & MODIS & $250-1000 \mathrm{~m}, 36$ bands (Vis-TIR) & \\
EO-1 & ALI & $30 \mathrm{~m}, 9$ bands (VNIR / SWIR) & \\
& Hyperion & $30 \mathrm{~m}, 220$ bands (hyperspectral) & \\
Envisat & AATSR & $1000 \mathrm{~m}, 7$ bands (VNIR-TIR) & ESA \\
Sentinel-2 & MERIS & $260 \mathrm{~m}-1200 \mathrm{~m}, 15$ bands (VNIR) & \\
& (planned 2013) & $10 / 20 / 60 \mathrm{~m}, 13$ bands (Vis-NIR-SWIR) & \\
SPOT-5 & HRG & $10 \mathrm{~m} ; 4$ bands (VNIR/SWIR) & CNES \\
ALOS & AVNIR-2 & $10 \mathrm{~m} ; 4$ bands (VNIR) & JAXA \\
ADEOS-II & GLI & $250-1000 \mathrm{~m}$; 36 bands (VNIR-SWIR-TIR) & \\
GCOM-C & SGLI & $250-1000 \mathrm{~m} ; 19$ bands (NearUV-TIR) & ISRO \\
Resourcesat-1 & AWiFS & $56 \mathrm{~m} ; 4$ bands (Vis-SWIR) & \\
Resourcesat-2 & AWiFS & $56 \mathrm{~m} ; 4$ bands (Vis-SWIR) & \\
& LISS-III & $23 \mathrm{~m} ; 4$ bands (Vis-SWIR) & \\
& LISS-IV & $5.8 \mathrm{~m} ; 3$ bands (VNIR) & CAST, \\
CBERS-2B & CCD & $20 \mathrm{~m}$; 4 bands (VNIR) & INPE \\
& IR-MSS & $80 \mathrm{~m}$ (SWIR), $160 \mathrm{~m}$ (TIR); 3 bands & \\
\hline
\end{tabular}

(AVIRIS) data and described a method for the first quantitative estimates of grain size from the snow reflectance at $1.03 \mu \mathrm{m}$ using the DIScrete-Ordinates Radiative Transfer model (DISORT; Stamnes et al., 1988). Bourdelles and Fily (1993) mapped grain size using TM band-4 $(0.85 \mu \mathrm{m})$, band$5(1.65 \mu \mathrm{m})$ and band-7 $(2.2 \mu \mathrm{m})$ data with a two-stream snow reflectance model over Terre Adélie, Antarctica. They found the estimated grain-sizes using TM band-4 much larger than grain size retrieved using TM band-5 and band- 7 . They observed that retrieved size depends on the radiation penetration depth, which is wavelength-dependent. Fily et al. (1997) made the comparison of in situ and Landsat TM derived snow grain characteristics in the Alps with theoretical results obtained from a bidirectional reflectance model (Stamnes et al., 1988). They reported linear relations between the measured grain sizes and the grain size derived from TM band-5 and band-7 data after an empirical correction of the reflectance and without the correction. Painter et al. (1998) mapped relative grain size at subpixel resolution using a linear spectral unmixing method from AVIRIS imagery over Mammoth mountain, California. Nolin and Dozier (2000) further made a hyperspectral method for snow grain size retrieval using imaging spectrometer AVIRIS data, which integrates across the entire $1.03 \mu \mathrm{m}$ absorption feature, which is scaled spectrally by its continuum. Li et al. (2001) retrieved snow grain size from near-infrared radiances at multiple wavelengths $0.86,1.05,1.24$ and $1.73 \mu \mathrm{m}$ from AVIRIS and found the retrieved snow grain size depend on wavelength. Painter et al. (2003) estimated and validated the subpixel snow cover and snow grain size using AVIRIS data. Their model analyzes multiple end member spectral mixtures with a spec- tral library of snow, vegetation, rock, and soil. They derived snow spectral endmembers of varying grain size from a radiative transfer model. Stamnes et al. (2007) developed the algorithms for grain size estimation using Global Imager (GLI) sensor channels $5(0.46 \mu \mathrm{m}), 19(0.865 \mu \mathrm{m})$ and $28(1.64 \mu \mathrm{m})$ at $1 \mathrm{~km}$ spatial resolution of Japan's ADEOSII satellite. They generated a set of lookup tables (LUTs) using a radiative transfer model to relate the reflectance of snow to grain size between 50 and $2000 \mu \mathrm{m}$ and the mass fraction of soot ranging from 0.02 to $2.5 \mathrm{ppmw}$ (parts per million by weight). Painter et al. (2009) retrieved the grain size and albedo from MODIS surface reflectance product (MOD09GA) and validated grain size retrievals with measurements made during the Cold Land Processes Experiment (http://nsidc.org/data/clpx/).

The snow retrieval algorithms using different satellite data as discussed above were developed using the representation of snowpack as a layer of dispersed spherical snow grains (Bohren and Barkstrom 1974; Warren and Wiscombe, 1980; Warren 1982; Stamnes et al., 1988). The scattering properties of snow grains were calculated using Mie theory. However, snow on ground consists of irregularly shaped nonuniform snow grains. The optical properties of snow are controlled by size and the shape of the particles (Mishchenko et al, 1999; Kokhanovsky, 2003; Kokhanovsky and Zege, 2004; Xie et al., 2006). Therefore more realistic snow models with non-spherical snow grains are proposed by different researchers (Kokhanovsky and Zege, 2004; Zege et al., 2008) and retrievals were made for different satellite sensors (Kokhanovsky et al., 2005, 2011a, b; Tedesco and Kokhanovsky, 2007; Lyapustin et al., 2009; Kokhanovsky 
and Schreier, 2009). Zege et al. (2011) developed a new algorithm based on the analytical solution for snow reflectance within the asymptotic radiative transfer theory for retrieval of the effective Snow Grain Size and Pollution amount (SGSP) from satellite measurements.

\subsection{Remote sensing of snow albedo}

Albedo is defined as the ratio of upwelling to down-welling radiative flux at the surface. Plane albedo is defined as albedo in the absence of a diffuse down-welling component and is a function of solar zenith angle and also called black-sky albedo or directional hemispherical reflectance. Spherical albedo is defined as albedo in the absence of a direct component when the diffuse component is isotropic and also called as white-sky albedo or bi-hemispherical reflectance. Dozier (1984) reported the use of Landsat-4 TM data for basin spectral albedo measurements using two-stream approximation model. Wanner et al. (1997) described the theory and algorithm to retrieve global maps of land surface BRDF and albedo (black sky and white sky albedo) for MODIS and MISR data. Its operational products MOD43 are available for the global and regional climate modeling communities (Schaaf et al., 2002; Moody et al., 2005). These products include black-sky albedo and white-sky albedo at seven spectral bands (MODIS bands 1-7), three broadbands (0.3-0.7, 0.7-5.0, and 0.3-5.0 $\mu \mathrm{m})$ and BRDF model parameters from which one can reconstruct the entire BRDF and compute the directional reflectance at any view or desired sun zenith angle. Since these products are available as a 16 days average, therefore not much suitable for seasonal snow cover monitoring of Himalayan region. The albedo of seasonal snow cover in Himalaya is highly variable due to varying temperature conditions with altitude and slopes, and snow metamorphism proceeds very fast. Kokhanovsky and Schreier (2009) retrieved spherical albedo using ART theory for AATSR data and showed the potential of ART theory for albedo determination using a single satellite pass.

High resolution spectral albedo is important to monitor surface characteristics, but for the total energy reflected by the earth's surface in the short-wave domain is characterized by the shortwave $(0.3-5.0 \mu \mathrm{m})$ broadband albedo. To estimate broadband albedo using satellite spectral bands normally requires the conversion of radiances into narrowband albedo, and then estimation of broadband albedo from the measurements at discrete wavelengths. Considerable work has been reported on broadband albedo using remote sensing with ground and laboratory validation that have provided observations under a variety of conditions (Brest and Goward, 1987; Liang, 2000; Klein and Stroeve, 2002; Liang et al., 2002; Greuell and Oerlemans, 2004; Stroeve et al., 2005). These studies have shown that the albedo of surfaces in the presence of snow can vary significantly, and therefore must be taken into account in radiative transfer calculations. Dozier et al. (2009) showed the relationship between grain size retrieved from AVIRIS imaging data and broadband albedo for fixed direct irradiance at $30^{\circ}$ and $60^{\circ}$ illumination angles (from zenith) for the visible and near infrared parts of the solar spectrum and all solar wavelengths. MODIS provides MOD10A daily broadband albedo product developed by Klein and Stroeve (2002) and Stroeve et al. (2006), but still requires the validation for Himalayan region due to its complex topography. In addition, the MODIS spatial resolution is coarse for Himalayan terrain therefore one can get only few pure snow pixels for the analysis. Hence, there is a need of a daily snow albedo and grain size product for many studies related to Himalayan snow cover.

All the above discussed studies in Sects. 1.1 and 1.2, have clearly shown the potential of remote sensing to retrieve snow characteristics using appropriate instrumentation. In this paper the asymptotic radiative transfer (ART) theory (Kokhanovsky and Zege, 2004) has been used to estimate quantitatively the snow grain size and spectral albedos for western Himalaya using Hyperion sensor data. In Sect. 2 the study area and data used is discussed and Sect. 3 describes the retrieval methodology using satellite data. We followed the bi-spectral methodology for grain size retrieval proposed by Kokhanovsky et al. (2011a, b). The performance of this theory for Himalayan snow cover is evaluated by Negi and Kokhanovsky (2011) using field measured reflectances. In Sect. 4 snow retrieval maps and their comparison with ground observed data are provided. The spatial variation of grain size and spectral albedo are also discussed. Finally, in Sect. 5, the salient features of the study and its importance are discussed.

\section{Study area and data used}

Sharma and Ganju (2000) characterized the western Himalaya in three zones, on the basis of snow climatic conditions, i.e. lower, middle and upper Himalayan zone (Fig. 1a and $b$ ). We have selected study area such that it can represent the each snow climatic zone. The lower Himalayan zone is characterized by moderate temperature, receives high precipitation and significant changes in the snow characteristics are due to moderate temperature. The altitude of this zone varies between 2000 and $4000 \mathrm{~m}$ and generally it covers the vegetation below $3000 \mathrm{~m}$. The study area selected for this zone consists of a part of Beas basin and a field snowmeteorological observatory of Snow and Avalanche Study Establishment (SASE) is located in this region at an altitude of $2900 \mathrm{~m}$, named here as "Station-1" (Fig. 1b). The other area selected from the middle Himalayan zone is a part of Bhaga basin. This zone is characterized by cold temperatures, mostly glaciated and altitude varies from 3500 to $5300 \mathrm{~m}$. Generally there is no vegetation. A field observatory of SASE is located in this region at the altitude $3800 \mathrm{~m}$ named as "Station-2" (Fig. 1b). The upper Himalayan zone is extremely cold, receives dry snow and having large area covered by glaciers and permanent snow which is somewhat 


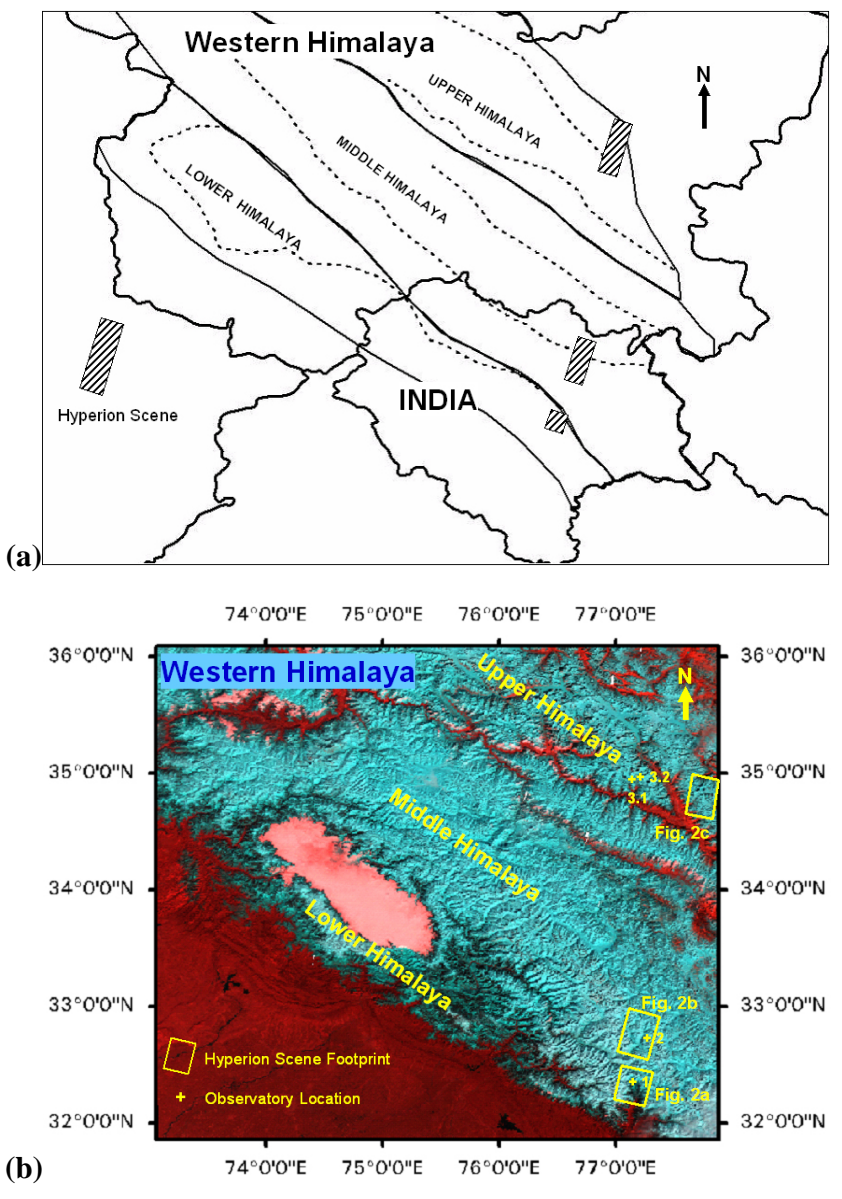

Fig. 1. (a) The layout of western Himalaya with different snow climatic zones and selected study areas; (b) satellite perspective view of western Himalaya with footprint of selected Hyperion scenes and corresponding observatory locations for each Himalayan zone.

close to continental snow conditions, and altitude is normally more than $5000 \mathrm{~m}$. A glaciated area of this zone is selected. Since there was no field observatory located exactly on this glaciated region, therefore we have selected two nearby field observatories of upper Himalayan zone for this study area. These observatory stations are approximately at the same altitude range $(5500 \mathrm{~m}$ and $6100 \mathrm{~m})$ which can represent this study area and named here as "Station-3.1 and Station-3.2" (Fig. 1b).

The field collected daily snow-meteorological data including maximum and minimum temperatures, fresh snowfall, snowpack thickness, age of snow, snow surface temperature, etc. recorded at these representative observatories were used for the ground validation. The detailed spectroradiometer survey was conducted in study area to understand the impact of different snow characteristics on snow reflectance and snow indices in lower Himalayan zone (Negi et al., 2009b and 2010). The ASD spectroradiometer (Field Spec Pro) was used to collect spectral reflectance $(350-2500 \mathrm{~nm}$ wavelength range) at a nadir-looking field of view. This spectrometer acquires spectral data at $1.4 \mathrm{~nm}$ intervals in the visible/NIR [380-1300 nm; full-width at half-maximum $(\mathrm{FWHM})=3-4 \mathrm{~nm}]$ and $2.2 \mathrm{~nm}$ in the SWIR region $(1300$ $2450 \mathrm{~nm} ; \mathrm{FWHM}=10-12 \mathrm{~nm}$ ). The snow grain sizes were estimated from field collected spectral reflectance measurements and used for the comparison.

Hyperion sensor data onboard NASA's EO-1 satellite (http://eo1.usgs.gov), was selected due to its spatial, spectral and radiometric resolution which is appropriate for $\mathrm{Hi}$ malayan terrain. Hyperion collects data in 220 unique spectral channels ranging from $357 \mathrm{~nm}$ to $2576 \mathrm{~nm}$ with approximately $10 \mathrm{~nm}$ bandwidth and 12 bit quantization (EO-1/ Hyperion science data user's guide). The instrument has a spatial resolution of $30 \mathrm{~m}$ for all bands with the standard swath width $7.7 \mathrm{~km}$. The available data was in 16-bit signed integer radiance values and for each pixel location, $242 \mathrm{spec}-$ tral channels of data are obtained. Spectral channels from 1-70 are collected from the VNIR and channels 71-242 are collected from the SWIR. Due to low signal for some channels, and to reduce the VNIR-SWIR overlap region, some of these spectral channels are not calibrated. The uncalibrated channels are set as zero values. The above characteristics of Hyperion sensor provide us to explore the suitable spectral bands for snow study. We have used only the five identified bands of Hyperion data for the snow retrievals i.e. wavelengths $440,500,1050,1240$ and $1650 \mathrm{~nm}$. These have corresponding band numbers 9, 15, 90, 109 and 150 . One can use the above multi-spectral data easily due to its smaller file size and faster processing in comparison to all 242 bands of hyperspectral data for operational monitoring of snow cover properties. The Hyperion sensor was tasked to acquire the desired region of lower and middle Himalaya and the data was collected on 5 March 2010, however, for the part of upper Himalayan zone, another image of 25 November 2003 selected. The lower Himalayan area acquired on 5 March 2010 (1040 local time) shows vegetation at lower altitude (brown area) and few cumulus clouds (Fig. 2a). The middle Himalayan study area acquired in the same satellite pass can be observed vegetation free with some low illuminated areas (Fig. 2b). The upper Himalayan part acquired on 25 November 2003, showing glaciated region and adjacent steep slopes as bare land (Fig. 2c). The selected scene size for the study area of lower, middle and upper Himalaya are $7.7 \mathrm{~km}$ in width and 13, 20 and $30 \mathrm{~km}$ in length respectively.

A good resolution digital elevation model (DEM) is important for the hilly terrain. The DEM for the part of lower and middle Himalayan zones study area were generated at SASE using contours and spot heights of 1:50 000 scale map sheets, and resampled at $30 \mathrm{~m}$ pixel resolution. For part of the upper Himalaya, an ASTER-derived DEM with $30 \mathrm{~m}$ spatial resolution was used, as the contour map sheet was not available to us for this area. These DEMs have been used for the generation of local incidence angle images and terrain corrected reflectance (Fig. 3), where bright and dark colour shows high and low illuminated areas. 


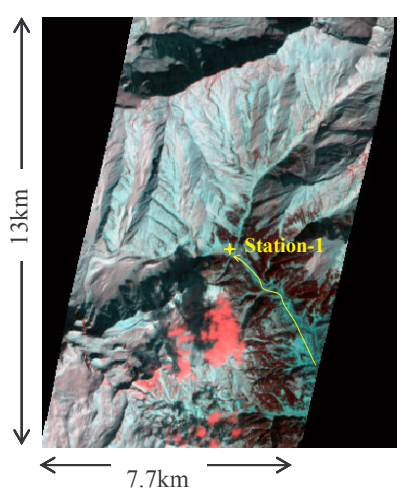

(a)

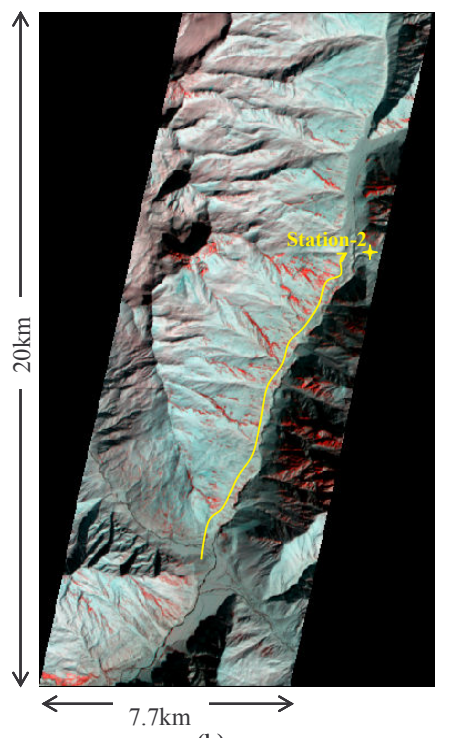

(b)

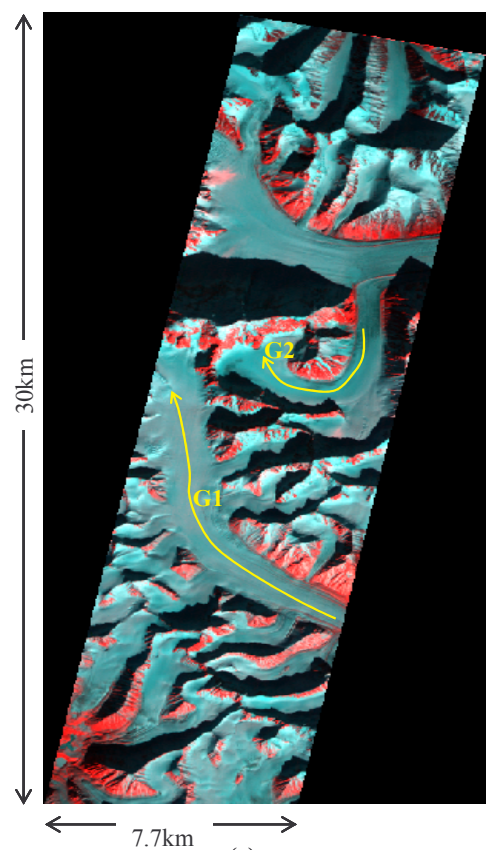

(c)

Fig. 2. The Hyperion images (FCC 440:500:1650 nm) of study area for the part of (a) lower Himalaya, (b) middle Himalaya and (c) upper Himalaya, with field stations and line drawn for spatial profile (yellow). The lengths of scenes marked are standard length and width of selected areas and the position of each scene is shown in Fig. $1 b$.
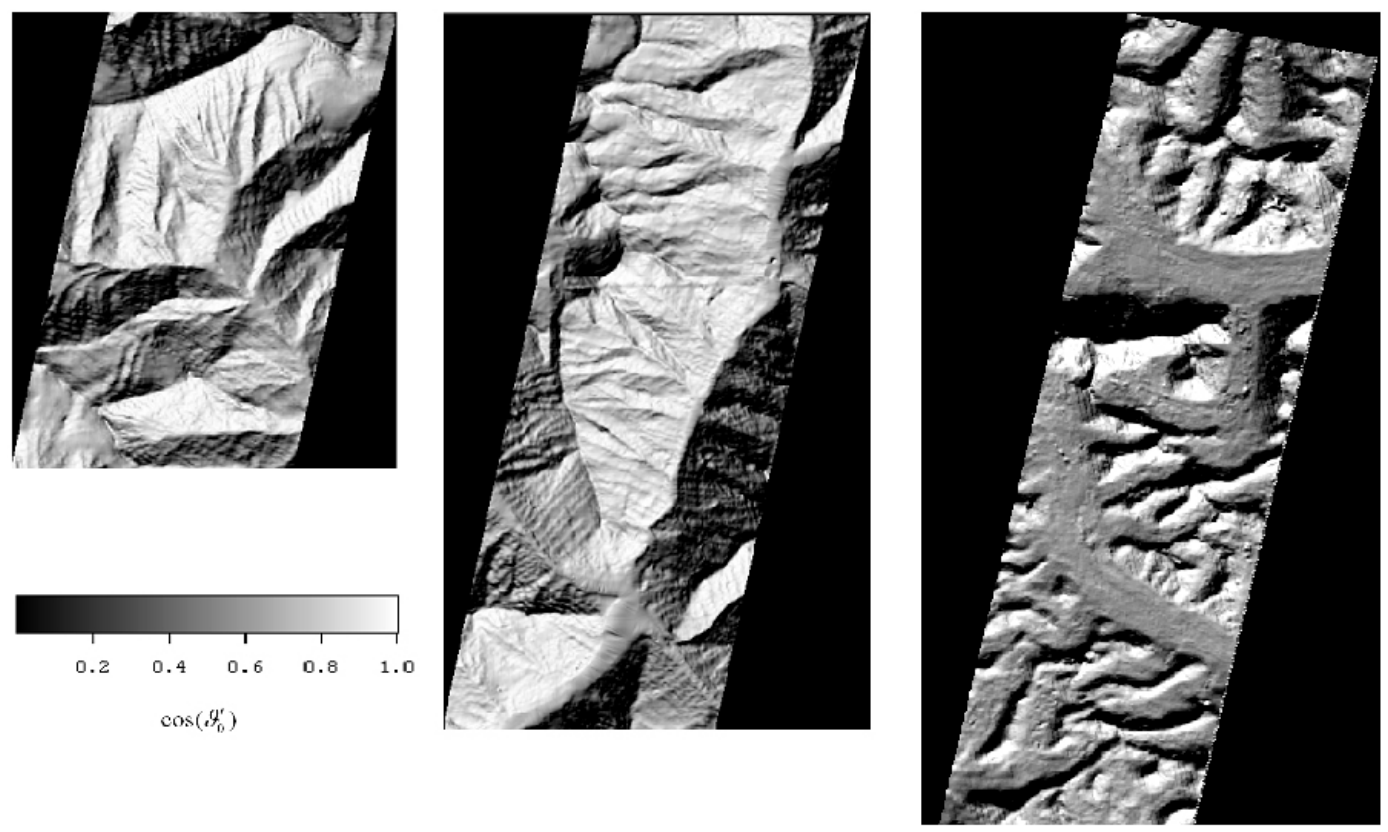

Fig. 3. The local incidence angle images generated using DEM for all the study areas.

\section{Methodology}

\subsection{Satellite data processing}

Hyperion Level-1Gst (L1Gst) digital images from EO-1 satellite, available in GeoTIFF format were preprocessed in
ENVI (Ver. 4.4) software and atmospheric correction was carried out using Fast Line-of-sight Atmospheric Analysis of Spectral Hypercubes (FLAASH) module based on the MODTRAN-4 radiative transfer code (Anderson et al., 1999; Cooley et al., 2002). FLAASH can accommodate all 
Table 2. The atmospheric correction using different atmospheric and aerosol models for the Hyperion images of the study area.

\begin{tabular}{|c|c|c|c|c|c|}
\hline Sr. No. & Study Area & Atmospheric model & Aerosol model & $\begin{array}{c}\text { Retrieved water } \\
\text { vapour }\left(\mathrm{gm} \mathrm{cm}^{-2}\right)\end{array}$ & $\begin{array}{l}\text { Legend in } \\
\text { Fig. } 4\end{array}$ \\
\hline \multirow{7}{*}{1.} & \multirow{7}{*}{ Lower Himalaya } & Sub Arctic Winter & 2-band KT & 0.1106 & AT1 \\
\hline & & Mid Latitude Winter & 2-band KT & 0.1947 & AT2 \\
\hline & & Tropical & 2-band KT & 0.7532 & AT3 \\
\hline & & $1135 \mathrm{~nm}$ water absorption feature & 2-band KT & 0.1839 & AT4 \\
\hline & & $820 \mathrm{~nm}$ water absorption feature & 2-band KT & 0.1997 & AT5 \\
\hline & & $1135 \mathrm{~nm}$ water absorption feature & Rural & 0.1828 & AT6 \\
\hline & & $1135 \mathrm{~nm}$ water absorption feature & Urban & 0.1839 & AT7 \\
\hline \multirow{7}{*}{2.} & \multirow{7}{*}{ Middle Himalaya } & Sub Arctic Winter & 2-band KT & 0.1106 & AT1 \\
\hline & & Mid Latitude Winter & 2-band KT & 0.1947 & AT2 \\
\hline & & Tropical & 2-band KT & 0.7532 & AT3 \\
\hline & & $1135 \mathrm{~nm}$ water absorption feature & 2-band KT & 0.1232 & AT4 \\
\hline & & $820 \mathrm{~nm}$ water absorption feature & 2-band KT & 0.2361 & AT5 \\
\hline & & $1135 \mathrm{~nm}$ water absorption feature & Rural & 0.1217 & AT6 \\
\hline & & $1135 \mathrm{~nm}$ water absorption feature & Urban & 0.1232 & AT7 \\
\hline
\end{tabular}

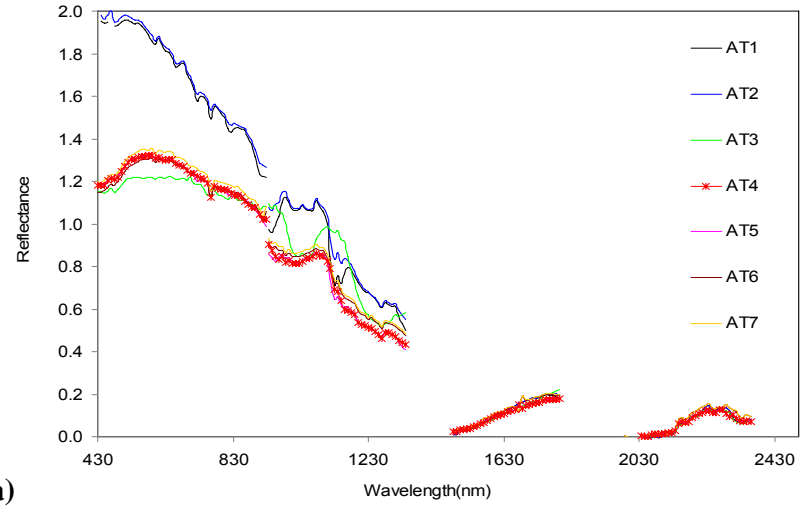

(a)

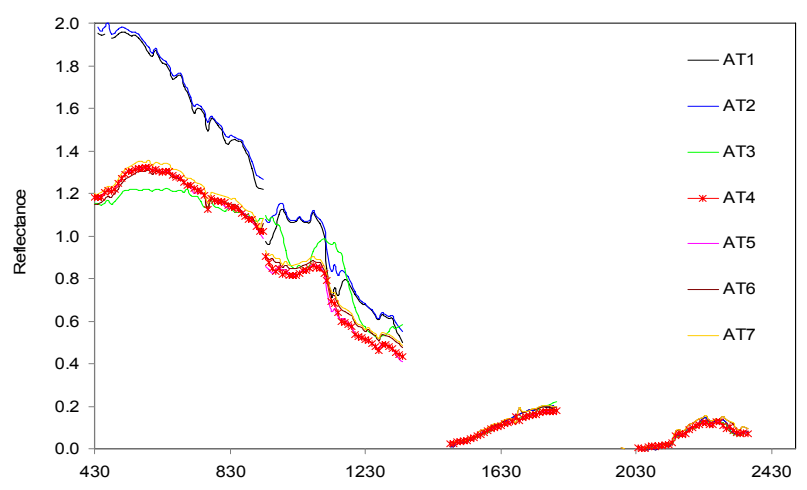

(b)

Fig. 4. The atmospheric corrected snow spectra from Hyperion image using different atmospheric and aerosol models for nearby area of (a) Station-1 of Lower Himalaya and (b) Station-2 of Middle Himalaya. The different legends are explained in Table 2.

parameters that influence atmospheric absorption and scattering such as relative solar position, aerosol and scattering models, visibility parameters, ozone total vertical column, adjacency effects (for flat areas only), artifact suppression, and provides water vapor retrieval (www.ittvis.com/ENVI). The atmospheric correction using different standard and derived atmospheric and aerosol models were attempted for the Hyperion data as shown in Table 2. A comparison between atmospheric corrected snow spectra using different models for nearby area of Station-1 and Station-2 of Lower and Middle Himalaya can be observed in Fig. $4 \mathrm{a}$ and $\mathrm{b}$ respectively. The retrieved water vapour for the scene and absorption due to ice at NIR channels 1050 and $1240 \mathrm{~nm}$ can be observed well for the atmospheric correction model AT4 in Fig. 4. Therefore the atmospheric model using water vapour absorption feature at $1135 \mathrm{~nm}$ wavelength for determining the column water vapor amount for each pixel in the image and 2band KT aerosol model (Kaufman et al., 1997) were used for the atmospheric correction. To make the methodology operational only five spectral bands (440, 500, 1050, 1240 and $1650 \mathrm{~nm}$ ) of Hyperion were further processed for snow retrievals.

The snow cover in Himalaya lies on the mountains and in order to understand the effect of topography on various snow parameters, topographic corrections are essential. We have applied the cosine correction method (Teillet et al., 1982) for topographic normalization, as this is a common and simplest correction method which is fast to make operational retrievals. The cosine correction, assumes that incident radiation is reflected in all directions equally i.e. lambertian reflectance characteristics and can be estimated using equation given by Teillet et al. (1982):

$R_{\mathrm{H}}=R_{\mathrm{T}} \times\left(\cos \left(\vartheta_{0}\right) / \cos \left(\vartheta_{0}^{\prime}\right)\right)$,

where $R_{\mathrm{H}}=\frac{\pi L_{\lambda}}{\cos \left(\vartheta_{0}\right) E_{0}}$ is the reflectance for horizontal surface, $L_{\lambda}$ is reflected radiance and $E_{0}$ is spectral irradiance. The $R_{\mathrm{T}}$ is the reflectance observed over the inclined terrain, 
$\cos \left(\vartheta_{0}\right)$ and $\cos \left(\vartheta_{0}^{\prime}\right)$ are cosines of solar zenith angle and local incidence angle respectively. The $\cos \left(\vartheta_{0}\right)$ can be calculated for a pixel using the formula given by Kasten (1962):

$\cos \left(\vartheta_{0}\right)=\cos (\xi) \cos (\delta) \cos (t)+\sin (\xi) \sin (\delta)$,

where $\xi$ is geographic latitude of the observer, $\delta$ is declination of the sun and $t$ is local hour angle of the sun (unit of all are in degree). Then $\cos \left(\vartheta_{0}^{\prime}\right)$ can be calculated using following equation (Smith et al., 1980):

$\cos \left(\vartheta_{0}^{\prime}\right)=\cos \left(\vartheta_{0}\right) \cos (e)+\sin \left(\vartheta_{0}\right) \sin (e) \cos (\Omega-\mathrm{As})$,

where $e$ is slope inclination; $\Omega$ is solar azimuth; and As is surface aspect of the slope angle. This cosine correction considers only direct irradiance although the proportion of diffuse skylight can be relatively high, particularly in weakly illuminated areas. For a low illumination, i.e., small values of $\cos \left(\vartheta_{0}^{\prime}\right)$, the corrected reflectance was too large and the corresponding parts of an image were overcorrected. In this case, very low illumination slopes i.e. $\vartheta_{0}^{\prime}>75^{\circ}$ were not selected for the analysis. In addition ART theory has large errors for $\vartheta_{0}^{\prime}>75^{\circ}$ (Kokhanovsky, 2004a). We have also attempted C-corrections (Riano et al., 2003) and modified Minnaert approach (Richter, 2009) for the topographic normalization, but did not find significant difference in the topographic corrected images. Secondly, even after this topographic correction in the snow covered mountainous terrain, few pixels in reflectance image remains overcorrected due to low illumination and 3-D adjacency effects. This was even observed at wavelength $1050 \mathrm{~nm}$, which can produce too small grain size in overcorrected regions. Therefore we have masked all the saturated pixels at wavelength $1050 \mathrm{~nm}$ for grain size retrieval.

To identify a snow pixel a criteria was made using normalized difference snow index (NDSI) and reflectance at visible wavelength band. The NDSI is defined as:

$\mathrm{NDSI}=\frac{R(\text { Visible })-R(\mathrm{SWIR})}{R(\text { Visible })+R(\mathrm{SWIR})}$,

where $R$ (Visible) and $R$ (SWIR) are the spectral reflectance in the visible and SWIR bands respectively. The visible wavelength $500 \mathrm{~nm}$ and SWIR wavelength $1650 \mathrm{~nm}$ were used for NDSI estimation. A threshold value of NDSI, which is normally used 0.4 for binary snow cover mapping (Hall et al., 1995) was raised to 0.6 , with a criteria that the visible channel $(500 \mathrm{~nm})$ reflectance should be greater than 0.6 to avoid fractional snow cover and heavy snow contamination (Negi et al., 2009b and 2010). The NDSI is also able to separate snow from cumulus clouds.

\subsection{Retrieval methods}

The ART theory was used to retrieve snow grain size and spectral albedo. According to this theory the snow reflection function can be modeled using approximate analytical solution in the form of the following equation valid for weakly absorbing snow layers (Kokhanovsky and Zege, 2004):

$R\left(\mu, \mu_{0}, \varphi\right)=R_{0}\left(\mu, \mu_{0}, \varphi\right) r_{s}^{f\left(\mu, \mu_{0}, \varphi\right)}$,

where $R\left(\mu, \mu_{0}, \varphi\right)$ is reflectance of a semi infinite snow layer; $\mu_{0}=\cos \vartheta_{0} ; \mu=\cos \vartheta ; \vartheta_{0}, \vartheta$ and $\varphi$ are solar zenith, viewing zenith and relative azimuth angles respectively. Also it follows:

$r_{s}=\exp \{-4 s / \sqrt{3}\}$ and $s=\sqrt{\frac{1-\omega_{0}}{1-g \omega_{0}}}$,

where, $r_{\mathrm{s}}$ is spherical snow albedo, $\omega_{0}$ is the single scattering albedo and $g$ is the asymmetry parameter. The function $f\left(\mu, \mu_{0}, \varphi\right)$ is given by the following ratio;

$f\left(\mu, \mu_{0}, \varphi\right)=\frac{u\left(\mu_{0}\right) u(\mu)}{R_{0}\left(\mu, \mu_{0}, \varphi\right)}$.

The function $u\left(\mu_{0}\right)$ is called the escape function. This function determines the angular distribution of light escaping from the semi-infinite non-absorbing media and is given approximately by (Kokhanovsky, 2003):

$u\left(\mu_{0}\right)=\frac{3}{7}\left(1+2 \mu_{0}\right)$.

The $R_{0}$ is the reflection function of a semi-infinite snow layer under assumption that the single scattering albedo is equal to one. It can be calculated using the approximation given by Kokhanovsky et al. (2005):

$R_{0}\left(\mu, \mu_{0}, \varphi\right)=\frac{\mathrm{A}+\mathrm{B}\left(\mu+\mu_{0}\right)+\mathrm{C} \mu \mu_{0}+p(\theta)}{4\left(\mu+\mu_{0}\right)}$,

where $\mathrm{A}=1.247, \quad \mathrm{~B}=1.186, \quad \mathrm{C}=5.157$, $p(\theta)=11.1 \exp (-0.087 \theta)+1.1 \exp (-0.014 \theta)$. The $\theta$ is given in degrees and defined as $\theta=a \cos \left(-\mu \mu_{0}+s s_{0} \cos \varphi\right)$, where $s=\sin (\vartheta)$ and $s_{0}=\sin \left(\vartheta_{0}\right)$.

In this study to estimate $R_{0}\left(\mu, \mu_{0}, \varphi\right)$ for hilly terrain, the values of different angles were calculated as shown in Fig. 5. Which shows, $\mu_{0}=\cos \left(\vartheta_{0}^{\prime}\right)$, where $\vartheta_{0}^{\prime}$ is local incidence angle calculated by Eq. (3); $\mu=\cos (e)$, where $e$ is the slope angle. For the present case, the satellite sensor was considered as nadir viewing (Y-axis). The satellite look angles (viewing angle) for 5 March 2010 and 25 November 2003 Hyperion scenes were observed $-2.5^{\circ}$ and $-0.47^{\circ}$ respectively, which can be considered as $0^{\circ}$ from nadir (i.e. nadir viewing). For calculating relative azimuth angle $\varphi$; the solar azimuth angle (SAA) was used at the time of satellite pass and viewing azimuth angle (VAA) was set as zero, due to consideration of nadir viewing sensor. The relative azimuth angle was calculated as $(180-($ SAA-VAA $))$. This is as per the consideration of ART theory, and satellite image file differs in this case by $180^{\circ}$. The satellite consider relative azimuth angle as zero, once the SAA and VAA are same but ART theory consider this as $180^{\circ}$. Further, function $f\left(\mu, \mu_{0}, \varphi\right)$ can be estimated by substituting $R_{0}$ and escape function Eq. (8). The 


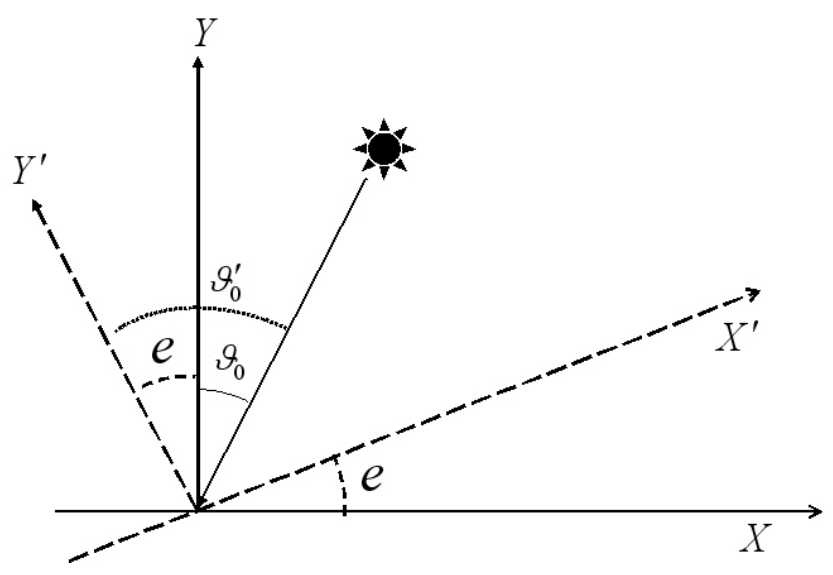

Fig. 5. A representation of incidence and viewing angles for plane to slope terrain.

value of asymmetry parameter $g$ was considered here as 0.76 (Kokhanovsky et al., 2011b).

\subsubsection{Grain size}

The effective optical size of snow grains is defined by the average volume $V$ and average projection area $S$ of a snow grain, and is represented as follows (Jin et al., 2008; Kokhanovsky et al., 2011b):

$a_{e f}=\frac{3}{4}(V / S)$.

The bi-spectral method (using one visible and one NIR channel) proposed by Kokhanovsky et al. (2011b), was used to estimate the snow grain size. The visible channel $(440 \mathrm{~nm})$ corresponds to light absorption due to the presence of soot and the NIR channel $(1050 / 1240 \mathrm{~nm})$ corresponds to light absorption due to ice and soot. Therefore this method accommodates any soot effects in the NIR channel. Negi and Kokhanovsky (2011) have found this method most suitable among four different methods of snow grain size retrieval using ART theory for Himalayan snow. The effective grain radius using this method can be defined by:

$a_{e f}=\left(b \alpha_{i, 2}\right)^{-1} \ln \left[\frac{\beta_{\infty}}{\beta_{\infty}-\beta_{i, 2}}\right]$,

where $\beta_{i, 2}$ is the probability of photon absorption (PPA) due to ice in NIR channel to retrieve grain size. The value of $b$ was considered 2.63 for fractals, $\alpha_{i, 2}$ is a linear absorption coefficient for ice $\alpha=4 \pi \chi(\lambda) / \lambda$ in NIR channel and $\beta_{\infty}$ is the limiting case of PPA for an ice crystal, which absorbs all radiation penetrated inside the particle $\left(\beta_{\infty}=0.47\right)$. This method is described in detail by Kokhanovsky et al. (2011b).

In the present study, grain size diameter $\left(d=2 \times a_{\mathrm{ef}}\right)$ was retrieved at two NIR channels 1050 and $1240 \mathrm{~nm}$. The $1050 \mathrm{~nm}$ wavelength is more sensitive to grain size but may contain some pollution effects, however channel $1240 \mathrm{~nm}$ is less sensitive to pollution but sometime the reflectance of old snow reaches less than $20 \%$, where the ART theory is not applicable. Secondly, grain size retrieval at two NIR channels can provide the grain size variation along vertical in snowpack.

\subsubsection{Albedo}

The spectral albedo (plane and spherical) of the medium is important for the estimation of integrated albedo as well as for the characterization of the medium in detail. However, to determine the integrated albedo the spectral distribution of the incident irradiance within each spectral band is also required. To compute the integrated albedo or broadband albedo $(0.3-5.0 \mu \mathrm{m})$ model from narrowband observations requires several levels of processing; this includes atmospheric correction, angular models to convert directional reflectance to spectral albedo, and narrowband to broadband conversion. The methods used to derive this conversion equation have ranged from field methods to modeling approaches. Further, conversion coefficients based on field methods under one specific atmospheric condition may not be applicable to other atmospheric and solar conditions, or one has to apply modeling approaches with simulating different types of surfaces, atmosphere, and viewing conditions which can be incorporated into analysis to produce accurate results. In the present study, while we are only retrieving the spectral albedo in five identified wavelength bands they can characterize the snow characteristics well, as snow albedo mainly depends on visible (dependence on contamination) and NIR (dependence on grain size) wavelengths.

The plane albedo is defined as the integral of reflectance function $R$ over all reflection (viewing) angles and defined as:

$r_{p}=\frac{1}{\pi} \int_{0}^{2 \pi} d \varphi \int_{0}^{1} R\left(\mu, \mu_{0}, \varphi\right) \mu d \mu$,

where $\mu$ is the cosine of viewing angle and $\varphi$ is the relative azimuth angle. The spherical albedo $\left(r_{\mathrm{s}}\right)$ is defined as the integral of plane albedo $\left(r_{\mathrm{p}}\right)$ over all solar angles, and is given by following equation:

$r_{\mathrm{s}}=2 \int_{0}^{1} r_{\mathrm{p}}\left(\mu_{0}\right) \mu_{0} d \mu_{0}$.

The albedo defined by Eqs. (12) and (13) is difficult to determine from satellite sensors because measurements are performed with fixed solar and viewing angles. Kokhanovsky et al. (2007) presented a possibility for direct determination of the spherical cloud albedo from single reflection function measurements for the special case of optically thick snow. This technique requires no a priori information on the particles size and optical thickness. It has also shown that the absolute value of error is below $3 \%$ at optical thickness $\tau \geq 10$ 
(a)
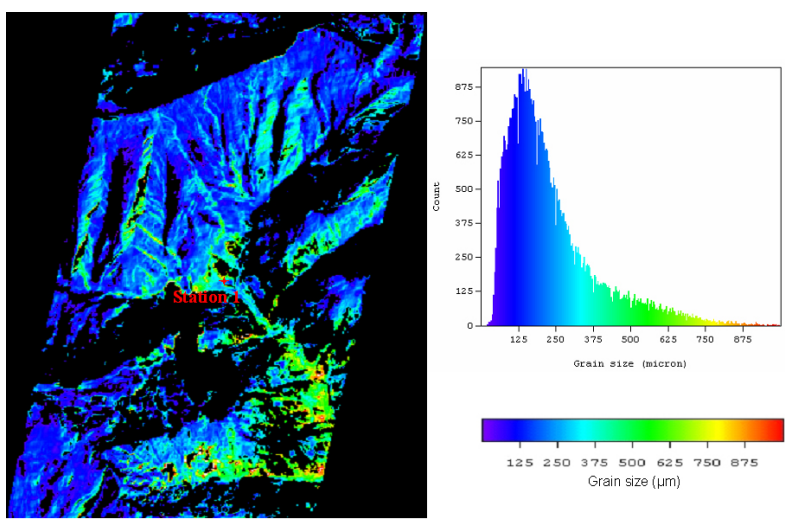

(b)
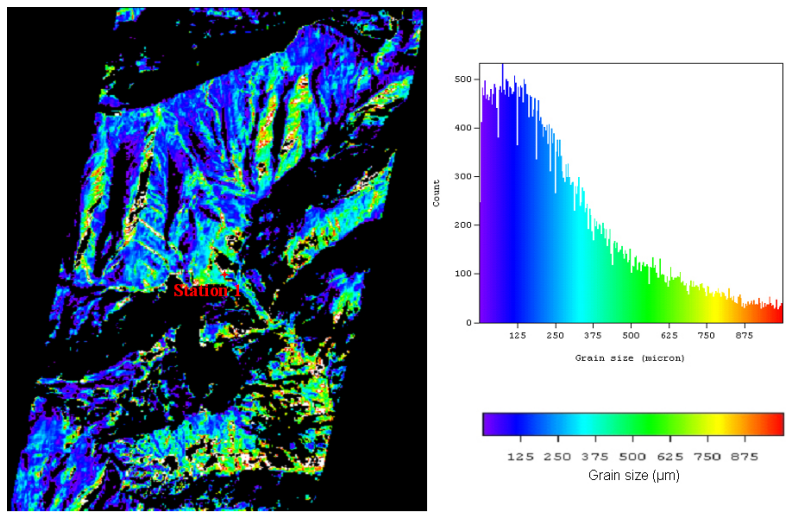

Fig. 6. The spatial distribution of snow grain size retrieved using (a) $1240 \mathrm{~nm}$ and (b) $1050 \mathrm{~nm}$ by Hyperion data for a part of lower Himalaya.

for all considered solar zenith angles and nadir observations, which is suitable in case of snow study. From Eq. (5), using the ART theory, spherical albedo $\left(r_{\mathrm{s}}\right)$, can be retrieved from satellite reflection measurement $(R)$ at a fixed geometry and can be given by following equation:

$r_{\mathrm{s}}=\left(\frac{R}{R_{0}}\right)^{1 / f}$.

Here $R$ is the atmospheric corrected reflectance and $f$, $R_{0}$ can be substituted from Eqs. (7) and (9) respectively. The plane albedo was retrieved using following relation (Kokhanovsky, 2004a):

$r_{\mathrm{p}}=\left(r_{\mathrm{s}}\right)^{u\left(\mu_{0}\right)}$,

where, $u\left(\mu_{0}\right)$ can be substituted from Eq. (8).

The retrieval of spectral albedo using Eqs. (14) and (15) were also validated by field measured spectral reflectances for Himalayan snow by Negi and Kokhanovsky (2011).

Further by retrieving the snow grain size $d$ spherical and plane albedo were also retrieved using equations given by Kokhanovsky and Zege (2004):

$r_{\mathrm{s}}=\exp (-b \sqrt{\alpha d)}$ (a)
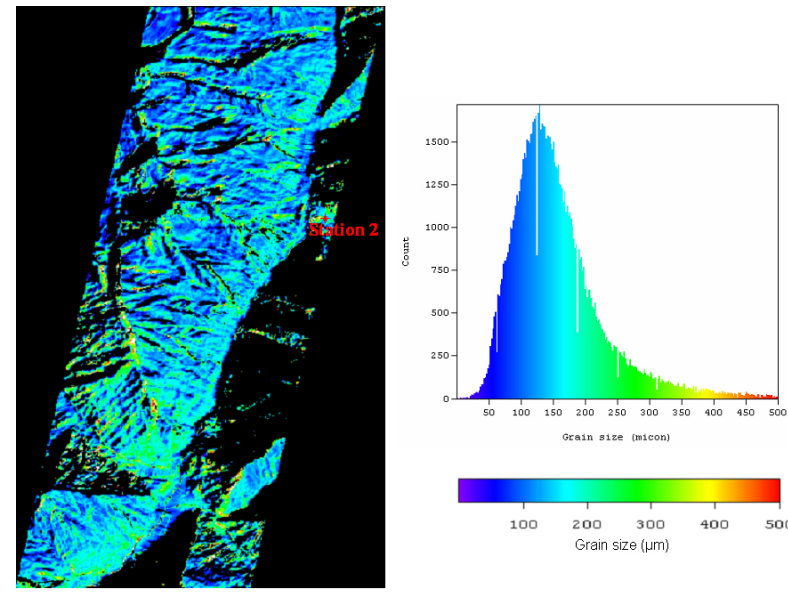

grain size (micon)
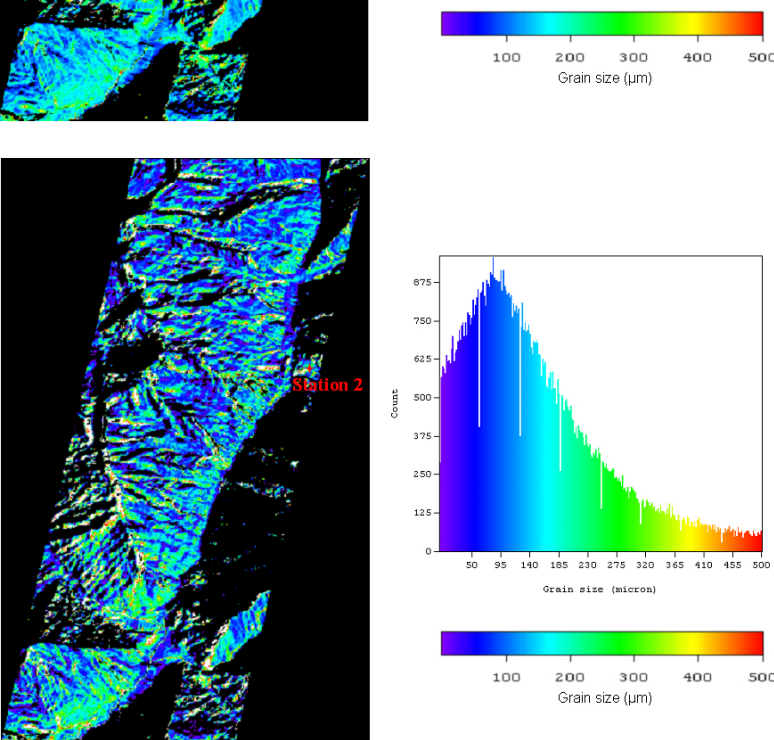

Grain size Imieron

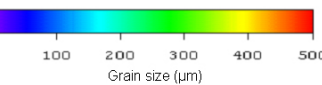

(b)

Fig. 7. The spatial distribution of snow grain size retrieved using (a) $1240 \mathrm{~nm}$ and (b) $1050 \mathrm{~nm}$ by Hyperion data for a part of middle Himalaya.

and

$r_{\mathrm{p}}=\exp \left(-u\left(\mu_{0}\right) b \sqrt{\alpha d}\right)$,

where $b$ is the shape factor and $\alpha$ is a linear absorption coefficient for ice.

For the comparison of grain size and spectral albedo retrieved by Hyperion with snow parameters at field station-1 and station-2, the open areas at these locations were selected in satellite scenes. Areas of $3 \times 3$ pixels at station- 1 and $4 \times 4$ pixels at station- 2 were selected at these locations, the average of retrieved snow parameter was estimated and used for the comparison. All the above discussed retrieval methods/equations were implemented in the model maker module of ERDAS Imagine software (Ver. 9.1). This provides an easy and fast coding to implement equations/functions on satellite data, and to produce the output maps. 
Table 3. Retrieved snow grain size in different study areas of western Himalaya, where SD is standard deviation.

\begin{tabular}{lccc}
\hline Study area & $\begin{array}{c}\text { NIR wavelength } \\
\text { used }(\mathrm{nm})\end{array}$ & $\begin{array}{c}\text { Mean grain } \\
\text { size }(\mu \mathrm{m})\end{array}$ & $\begin{array}{c}\text { SD } \\
(\mu \mathrm{m})\end{array}$ \\
\hline \multirow{2}{*}{ Lower Himalaya } & 1240 & 238 & 164 \\
& 1050 & 321 & 285 \\
Middle Himalaya & 1240 & 161 & 087 \\
& 1050 & 187 & 188 \\
Upper Himalaya & 1240 & 418 & 248 \\
& 1050 & 475 & 340 \\
\hline
\end{tabular}

\section{Results and discussions}

\subsection{Grain size in lower and middle Himalaya}

Figure 6 shows the retrieved grain size map for a part of the lower Himalaya on 5 March 2010 using NIR band 1240 and $1050 \mathrm{~nm}$ respectively. The criteria of selecting snow pixel is able to mask (black areas) the cloud, snow mixed vegetation, snow free and shadow or low illuminated areas. The spatial variation in grain size can be observed in the selected study area with mountainous terrain i.e. elevation, slopes and aspect. The average grain size for the complete selected study area was observed around 238 and $321 \mu \mathrm{m}$ using wavelength 1240 and $1050 \mathrm{~nm}$ respectively (Table 3 ). The representative observatory location of this area i.e. station- 1 shows the retrieved grain size around 239 and $308 \mu \mathrm{m}$ at wavelengths 1240 and $1050 \mathrm{~nm}$ respectively (Table 4). Figure 7 shows the retrieved grain size map for the part of middle Himalaya, where very low illuminated areas are masked well (black areas). The average grain size was observed 161 and $187 \mu \mathrm{m}$ for this study area, and 183 and $216 \mu \mathrm{m}$ at station-2 using wavelengths 1240 and $1050 \mathrm{~nm}$, respectively (Tables 3 and 4). The larger grain size retrieved using wavelength $1050 \mathrm{~nm}$ compared to $1240 \mathrm{~nm}$ can be explained by the fact that the retrieved grain size depends on radiation penetration depth, which is wavelength dependent (Bourdelles and Fily, 1993; $\mathrm{Li}$ et al., 2001). The vertical homogeneity of snowpack can also be defined by the ratio of retrieved grain size at the $1050 \mathrm{~nm}$ to the $1240 \mathrm{~nm}$ wavelength channels, and we found this ratio 1.29 at the station- 1 and 1.18 at station-2. This shows that snow at station- 2 is more vertically homogeneous than at station-1.

For the field validation of retrieved snow grain sizes, unfortunately we do not have in situ grain size data at the time of satellite pass, but the snow-meteorological data recorded at station- 1 and station- 2 on 5 March 2010 at 08:30 (forenoon) and 17:30 (afternoon) local time (LT) are useful for the validation. This can help in understanding the field snow cover conditions by snow age, temperatures pattern and sun shine duration, as these factors are important
Table 4. Grain size retrieved at station-1 of lower Himalaya and station-2 of middle Himalaya; vertical homogeneity is the ratio of retrieved grain size at the $1050 \mathrm{~nm}$ to the $1240 \mathrm{~nm}$ wavelength channels.

\begin{tabular}{lccc}
\hline Field station & $\begin{array}{c}\text { Grain size }(\mu \mathrm{m}) \\
\text { using } 1240 \mathrm{~nm}\end{array}$ & $\begin{array}{c}\text { Grain size }(\mu \mathrm{m}) \\
\text { using } 1050 \mathrm{~nm}\end{array}$ & $\begin{array}{c}\text { Vertical } \\
\text { homogeneity }\end{array}$ \\
\hline Station-1 & 239 & 308 & 1.29 \\
Station-2 & 183 & 216 & 1.18 \\
\hline
\end{tabular}

for snow metamorphism process. Both the above discussed study areas received new snowfall before the satellite pass (Table 5). The fresh snowfall at the station-1 and station-2 were $111 \mathrm{~cm}$ and $19 \mathrm{~cm}$ respectively and the standing snow of $152 \mathrm{~cm}$ and $163 \mathrm{~cm}$ were observed at these stations at 08:30 LT. The maximum temperature on the day of satellite pass (5 March 2010) was observed $+7^{\circ} \mathrm{C}$ at station-1, and $-1{ }^{\circ} \mathrm{C}$ at station-2. The near positive air temperature in the lower Himalayan area decreased the high degree of dendricity (due to new snow) and increased the average effective grain sizes. In addition, grain sizes of both the areas are compared with temporal (hourly) retrieved grain sizes using field spectroradiometer of passed winters. One such field investigation was carried out during the similar mid winter period on 29 January 2005 in lower Himalayan region for new snow i.e. day-1 after snow storm. A very good agreement was observed for lower Himalayan region between grain sizes using Hyperion sensor at 10:40 LT i.e. 238-321 $\mu \mathrm{m}$ (Table 3) and the retrieved grain size using spectroradiometer at 10:45 LT (Table 6). This agreement is due to generally moderate temperature conditions prevailing in this zone which changes grain size quickly after a snowfall once the temperature starts rising during the day. Secondly the field spectroradiometer experiments were conducted in this region where similar climatic conditions prevail. However, the satellite retrieved grain sizes in the middle Himalayan area of around 161-187 $\mu \mathrm{m}$ (Table 3) can be compared well with retrieved grain sizes at 10:20 LT in field (Table 6). This is again due to comparatively slow thermal metamorphism in middle $\mathrm{Hi}$ malaya, as the air temperature was at sub zero and snow surface temperature was also observed very low after the snow storm (Table 5). In the present study, we cannot establish the correlation between retrieved and measured snow grain sizes at ground, but Kokhanovsky et al. (2011b) validated the applied bi-spectral grain size algorithm for MODIS sensor data (temporally and spatially) with ground measured snow grain sizes using optical microscopy in Hokkaido (Japan). They found a good correlation of 0.71 for grain size retrieved using channel $1240 \mathrm{~nm}$ wavelength. They also found their results of retrievals similar to those derived using independent grain size retrieval algorithm developed at JAXA (Stamnes 
Table 5. Field collected snow meteorological data recorded at 08:30 (F) and 17:30 (A) local time for representative stations of lower and middle Himalaya.

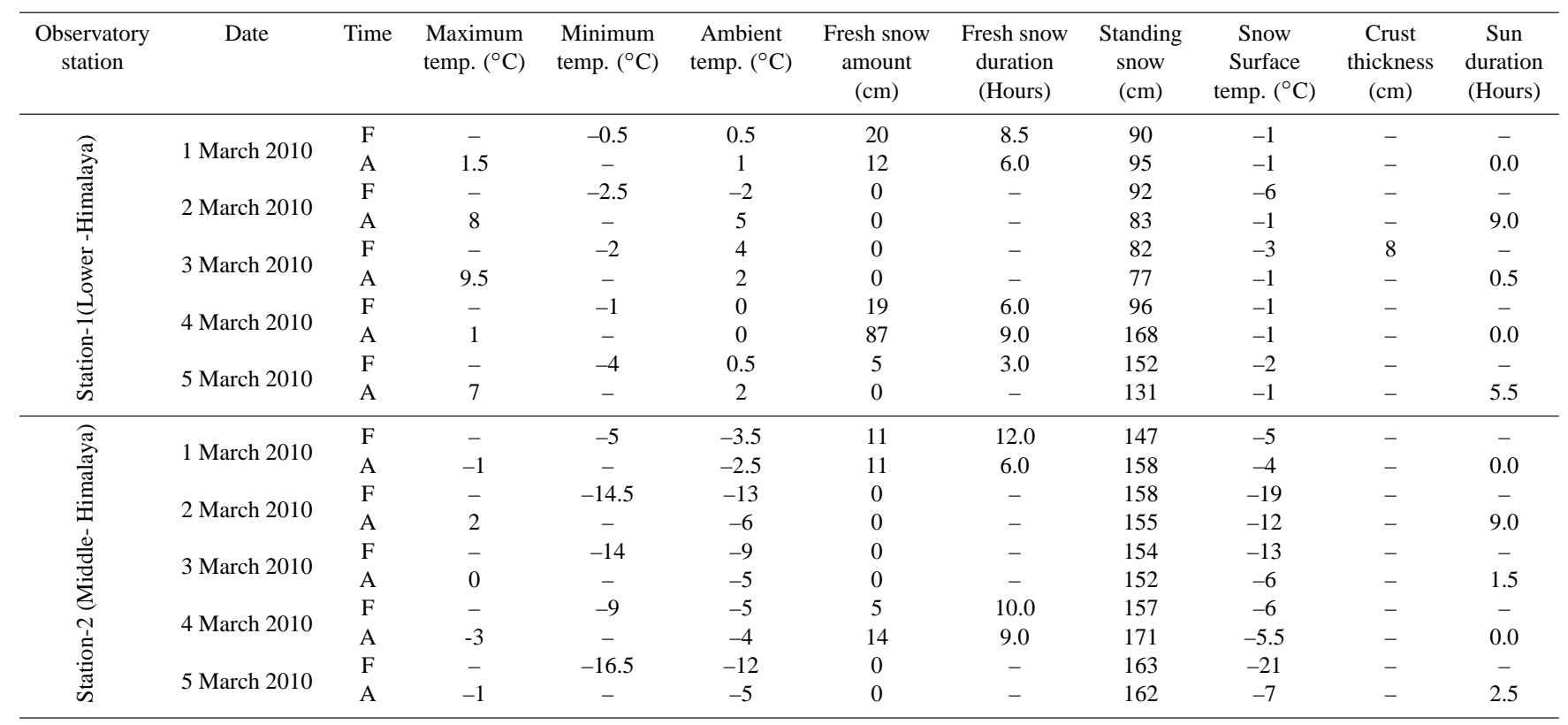

Table 6. Snow grain size retrieved using field spectroradiometer in lower Himalayan area.

\begin{tabular}{|c|c|c|c|c|}
\hline \multirow{2}{*}{$\begin{array}{l}\text { Snow type } \\
\text { and date of } \\
\text { observation }\end{array}$} & \multirow{2}{*}{$\begin{array}{c}\text { Time of } \\
\text { observation } \\
\text { (LT) }\end{array}$} & \multirow{2}{*}{$\begin{array}{c}\text { Surface } \\
\text { Temperature } \\
\left({ }^{\circ} \mathrm{C}\right)\end{array}$} & \multicolumn{2}{|c|}{$\begin{array}{l}\text { Grain size retrieved using } \\
\text { bi-spectral method }(\mu \mathrm{m})\end{array}$} \\
\hline & & & 443 and $1240 \mathrm{~nm}$ & 443 and $1050 \mathrm{~nm}$ \\
\hline \multirow{6}{*}{$\begin{array}{l}\text { Snow day-1 after } \\
\text { storm } \\
29 \text { January } 2005\end{array}$} & 09:30 & -2.0 & 140 & 136 \\
\hline & $10: 20$ & -2.0 & 147 & 158 \\
\hline & $10: 45$ & -1.5 & 312 & 265 \\
\hline & $11: 20$ & 0.0 & 328 & 346 \\
\hline & $11: 50$ & 0.0 & 511 & 454 \\
\hline & $12: 20$ & 0.0 & 908 & 764 \\
\hline
\end{tabular}

et al., 2007). However, such correlation can be improved if the measurement of grain sizes can be made using light reflectance at the ground and not the optical microscopy.

The standard deviation of the grain sizes (i.e. SD) shows the spatial grain size variation in selected study areas. A large variation in SD of grain sizes can be observed in lower Himalayan region compared to middle Himalaya (Table 3). This may be due to significant temperature variation due to the altitudes and slopes of selected lower Himalayan region. Further, the spatial profiles of snow grain size (Fig. 8) along the area marked as in Fig. 2a, shows grain size varies significantly from around 600 to $200 \mu \mathrm{m}$ along the approach road to station- 1 and almost constant grain size observed $(\sim 180 \mu \mathrm{m})$ along the approach road to station-2, in middle Himalaya. The altitude variation along the spatial profile of lower Hi- malaya (Fig. 8a) is from $2400 \mathrm{~m}$ to $2900 \mathrm{~m}$, and further the temperature being close to $0^{\circ} \mathrm{C}$ in this area, makes this significant to increase the grain size variation. The altitude variation is negligible for profile Fig. 8b, and being sub zero temperature of this area, the grain size variation was observed negligible along the spatial profile. Thus the spatial and vertical snow grain size variations can be observed well in two different snow climatic study areas using satellite sensor.

\subsection{Grain size in upper Himalaya}

The grain size map for the part of upper Himalaya shows the complete spatial distribution of grain size along the glaciers (Fig. 9), this shows that the present methodology is well suited to make the snow retrievals for gradual slopes, like 
Table 7. Snow meteorological data recorded at 08:30 (F) and 17:30 (A) local time at two different stations of upper Himalaya.

\begin{tabular}{lllllllll}
\hline Station & Date & Time & $\begin{array}{l}\text { Max. } \\
\text { Temp. } \\
\left({ }^{\circ} \mathrm{C}\right)\end{array}$ & $\begin{array}{l}\text { Min. } \\
\text { Temp. } \\
\left({ }^{\circ} \mathrm{C}\right)\end{array}$ & $\begin{array}{l}\text { Air } \\
\text { Temp. } \\
\left({ }^{\circ} \mathrm{C}\right)\end{array}$ & $\begin{array}{l}\text { Snow } \\
\text { age } \\
(\text { day })\end{array}$ & $\begin{array}{l}\text { Standing } \\
\text { snow } \\
(\mathrm{cm})\end{array}$ & $\begin{array}{l}\text { Snow } \\
\text { Temp. } \\
\left({ }^{\circ} \mathrm{C}\right)\end{array}$ \\
\hline \multirow{2}{*}{ Station-3.1 } & \multirow{2}{*}{ 25 November 2003 } & $\mathrm{F}$ & - & -31 & -22.5 & 7 & 27 & -30 \\
& & $\mathrm{~A}$ & -11.5 & - & -12 & 7 & 26 & -20 \\
\hline \multirow{2}{*}{ Station-3.2 } & \multirow{2}{*}{ 25 November 2003 } & $\mathrm{F}$ & - & -37 & -25 & 7 & 15 & -35 \\
& & $\mathrm{~A}$ & -10 & - & -15 & 7 & 15 & -33 \\
\hline
\end{tabular}

Table 8. Comparison of spectral albedo at station-1 (lower Himalaya) and station-2 (middle Himalaya) with SZA: $46.8^{\circ}$.

\begin{tabular}{lcccccc}
\hline \multirow{2}{*}{$\begin{array}{l}\text { Wavelength } \\
(\mathrm{nm})\end{array}$} & \multicolumn{2}{c}{ Reflectance } & \multicolumn{2}{c}{ Plane albedo } & \multicolumn{2}{c}{ Spherical albedo } \\
& Station-1 & Station-2 & Station-1 & Station-2 & Station-1 & Station-2 \\
\hline 440 & 0.84 & 0.86 & 0.79 & 0.84 & 0.83 & 0.85 \\
500 & 0.89 & 0.92 & 0.83 & 0.89 & 0.86 & 0.89 \\
1050 & 0.66 & 0.72 & 0.64 & 0.73 & 0.71 & 0.74 \\
1240 & 0.43 & 0.51 & 0.43 & 0.54 & 0.52 & 0.56 \\
1650 & 0.10 & 0.12 & 0.12 & 0.16 & 0.19 & 0.18 \\
\hline
\end{tabular}

on glaciers. The average grain size retrieved on 25 November 2003 over the upper Himalayan area was around 418 and $475 \mu \mathrm{m}$ using wavelength 1240 and $1050 \mathrm{~nm}$ respectively (Table 3). The possible reason of the large grain size could be the snow metamorphism due to aging, as the snow fall took place 7 days before the satellite observation (Table 7). The metamorphism can take place even at very low temperature as observed snow surface temperatures were in the range of -20 to $-35^{\circ} \mathrm{C}$ (Table 7), but especially in the presence of a temperature gradient through the snowpack or during surface hoar snow grain formation. Therefore it can be only validated with additional field data of snowpack, which presently we do not have. The temporal grain size profiles along the glacier (Fig. 8c) can be an important input for glacier study such as equilibrium line altitude (ELA) and albedo estimation from grain size.

It was observed that the NIR wavelength $1240 \mathrm{~nm}$ is more suitable compared to wavelength $1050 \mathrm{~nm}$, for snow grain size retrieval in the Himalaya as a wavelength of $1240 \mathrm{~nm}$ was found less affected by complex topography of Himalaya such as 3-D adjacency effects and this was observed for all the histograms of reflectances at $1240 \mathrm{~nm}$. Figure 10 shows the spatial distribution of reflectance at $1240 \mathrm{~nm}$ for middle Himalaya and its dependence on grain size can be observed well in Fig. 7a. Secondly grain size retrieved using wavelength $1240 \mathrm{~nm}$ is more stable as it is less sensitive to atmospheric effects and contamination. This problem is not significant in the gradual slope area like in glaciers of upper Himalaya, where grain size using both the channels is more feasible.

\subsection{Albedo}

The spectral albedo (plane and spherical) at five wavelength bands were retrieved from satellite observed reflectances using simple analytical equations (Eqs. 14 and 15). This is the advantage of ART theory that using single reflectance measurement the spectral albedo can be retrieved (Kokhanovsky et al., 2007). The comparison of spectral albedo of snow between station- 1 and station- 2 are shown in Table 8 . The reflectance at station- 2 is higher at all the five spectral bands. The higher reflectance at NIR channels at station-2 also proves smaller grain size compared to station-1. The difference between spectral reflectance and albedo is due to snow reflectance anisotropy, as reflected radiation from snow surface does not distribute uniformly into all angles. Further spherical albedo is observed higher than plane albedo for the solar zenith angle (SZA) $46.8^{\circ}$ at the time of image acquisition. This is because in the case of diffuse radiation, the albedo increases with SZA below $50^{\circ}$ (i.e. now spherical albedo) and decreases above $50^{\circ}$ (Wiscombe and Warren, 1980). Due to the same reason, at the higher $\mathrm{SZA}\left(58.5^{\circ}\right)$ for upper Himalayan area the spherical albedo can be observed less than plane albedo (Table 9).

The spherical and plane albedos can alternately also be retrieved using the snow grain size (Fig. 11). The advantage of this method is that spectral albedo can be generated for all the wavelengths up to $1400 \mathrm{~nm}$, once the imaginary part of ice refractive index is known. For wavelengths beyond $1400 \mathrm{~nm}$ the error increases in modeled reflectances due to limitation of ART theory, as the theory only valid for low absorption 
Table 9. Spectral plane and spherical albedo of upper Himalayan zone with SZA: $58.5^{\circ}$.

\begin{tabular}{lcccccc}
\hline \multirow{2}{*}{$\begin{array}{l}\text { Wavelength } \\
(\mathrm{nm})\end{array}$} & \multicolumn{2}{c}{ Mean } & \multicolumn{2}{c}{ Mode } & \multicolumn{2}{c}{ SD } \\
& Plane & Spherical & Plane & Spherical & Plane & Spherical \\
\hline 440 & 0.88 & 0.88 & 0.91 & 0.88 & 0.18 & 0.20 \\
500 & 0.92 & 0.92 & 0.94 & 0.92 & 0.19 & 0.21 \\
1050 & 0.69 & 0.68 & 0.72 & 0.69 & 0.16 & 0.16 \\
1240 & 0.49 & 0.46 & 0.51 & 0.46 & 0.12 & 0.10 \\
1650 & 0.31 & 0.25 & 0.32 & 0.27 & 0.06 & 0.05 \\
\hline
\end{tabular}

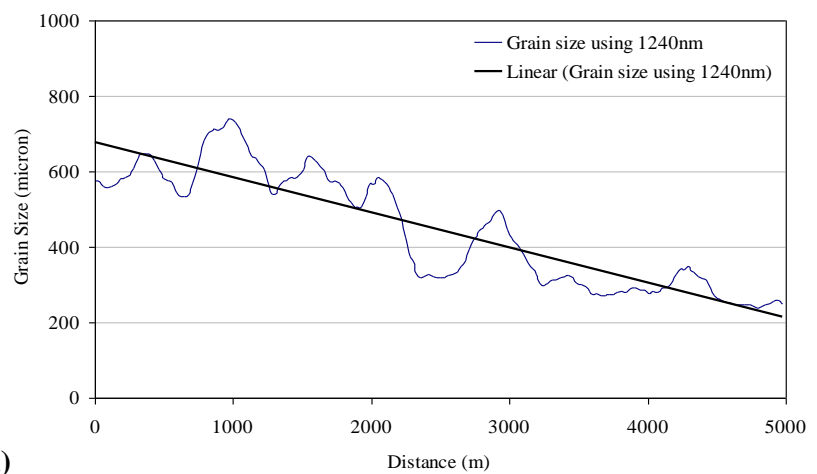

(a)

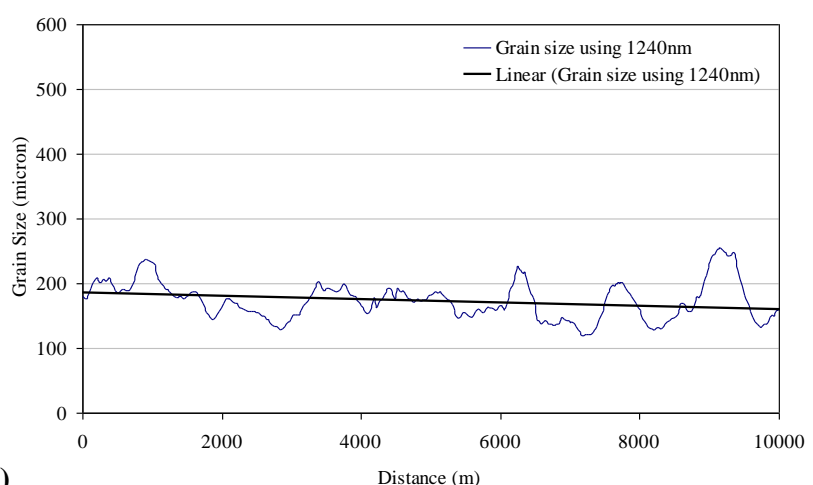

(b)

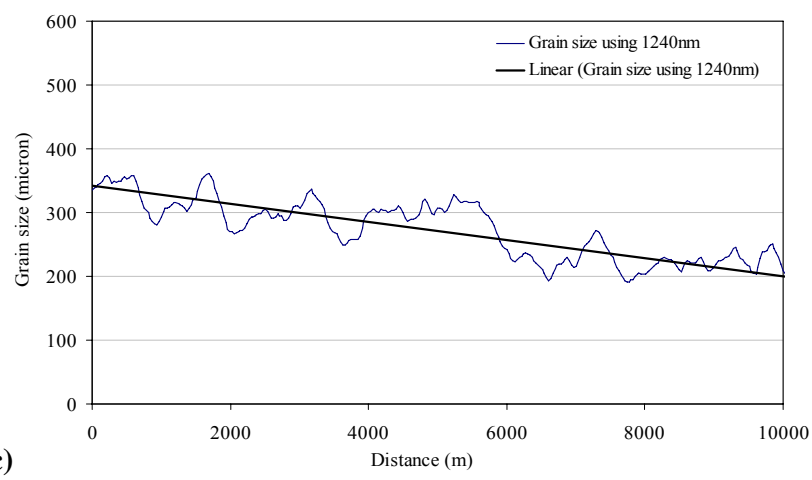

Fig. 8. Spatial profile of grain size traversed along approach road to (a) station-1 in lower Himalaya, (b) station-2 in middle Himalaya and (c) glacier (G1) profile from ablation to accumulation area; the marked profiles can be observed in Fig. (2) by yellow line. (a)
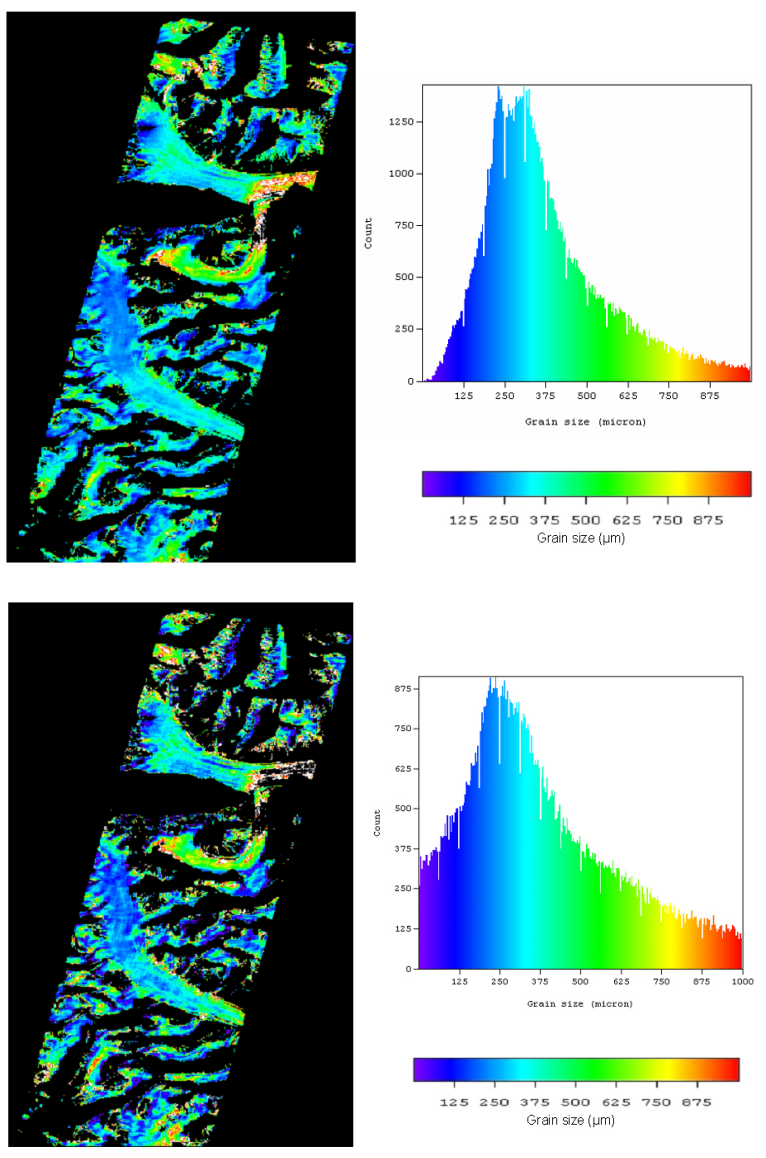

125250375500625750875 Grain size $(\mu m)$

Fig. 9. The spatial distribution of snow grain size retrieved using (a) $1240 \mathrm{~nm}$ and (b) $1050 \mathrm{~nm}$ by Hyperion data for a part of upper Himalaya.

(Kokhanovsky and Zege, 2004). The modeled albedo can be observed well in agreement in NIR region for both the stations, where the albedo is controlled by grain size. But for the visible region it can approximately work well in case of only pure snow, as the visible albedo changes significantly by slight contamination in snow. Therefore, we feel retrieval of spectral albedo using satellite reflectances at visible and NIR channels has more advantage in describing the snow cover properties. 

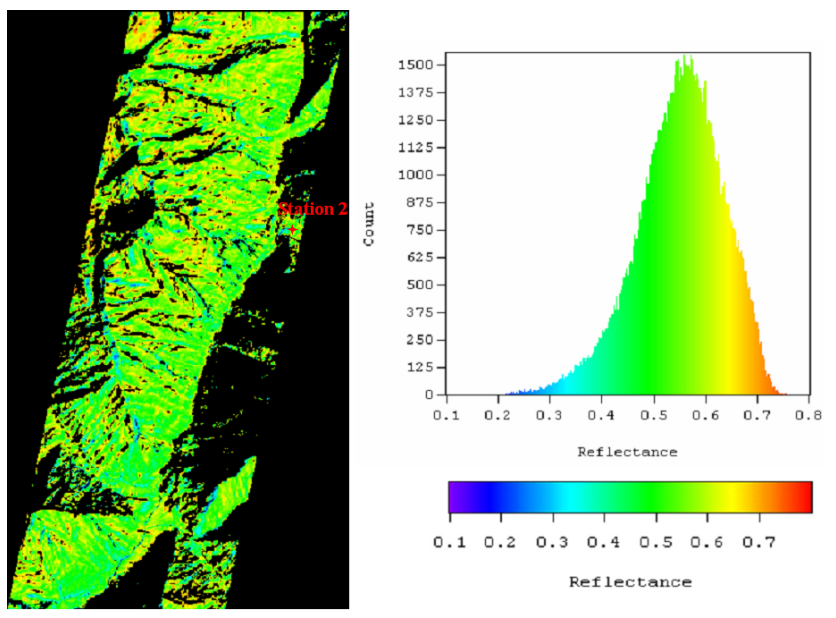

Fig. 10. The spatial distribution of reflectance at $1240 \mathrm{~nm}$ and its histogram measured by Hyperion data over a part of middle Himalaya.

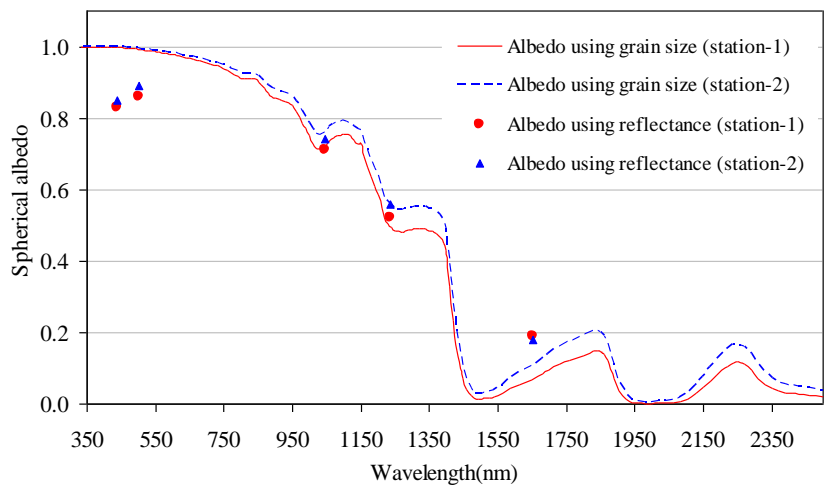

Fig. 11. The comparison between spherical albedo retrieved using grain size and retrieved from the satellite reflectances for station-1 and station- 2 .

To understand the significant difference in snow grain size of two adjacent glaciers (G1 and G2) of upper Himalaya (as marked in Fig. 2c and grain size map Fig. 9), the spectral albedo profiles from the ablation zone to accumulation zone along the glaciers at wavelength 500, 1050 and $1240 \mathrm{~nm}$ have been drawn (Fig. 12). The presence of high spectral albedo at $500 \mathrm{~nm}$ shows that the glacier G2 is not contaminated or exposed (mixed pixels), and the large grain sizes computed for glacier G2 are due to low spherical albedo (reflectance) at NIR wavelengths. Further, different aspects of both the glaciers (i.e. G1 with south-east and G2 with north-east) may be the reason of grain size variations due to different rate of metamorphism. Therefore, spectral albedo retrieval using satellite data can also provide useful input for glacier study.

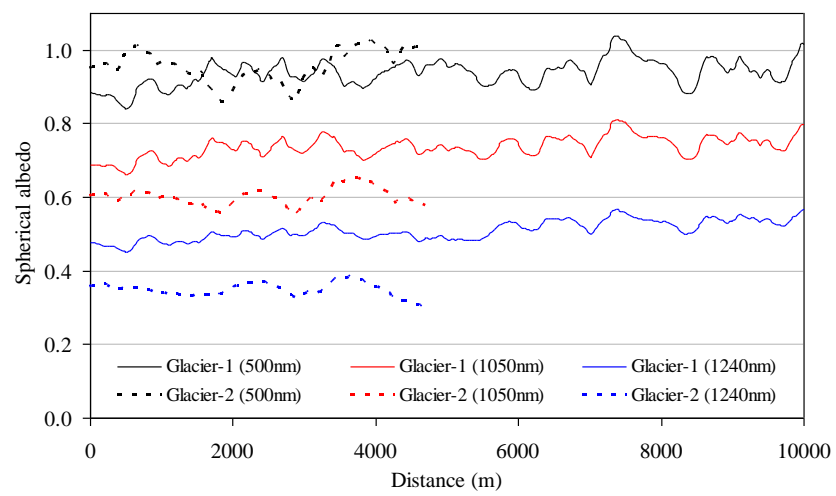

Fig. 12. The spatial profile of spectral albedo along the two selected glaciers of upper Himalaya (spatial profile marked as in Fig. 2c).

\section{Conclusions}

The ART theory was applied to retrieve snow grain size and albedo using satellite data for western Himalayan snow cover. The main advantage of ART theory is simple approach using analytical equations as compared to other radiative transfer theories for retrieving the snow characteristics. To make this methodology operational a spectral subset of the 242 Hyperion bands was used to reduce the time and memory space in processing the hyperspectral data and because hyperspectral scene contains redundant information. The methodology can mask the cumulus clouds, shadow regions, patchy and heavy contaminated snow cover area.

The grain size retrieved using NIR wavelength channels at 1050 and $1240 \mathrm{~nm}$ along with visible channel at $440 \mathrm{~nm}$ which can accommodate absorption due to soot in NIR exists. The average retrieved grain size using $1050 \mathrm{~nm}$ were found to be larger than grain size retrieved using $1240 \mathrm{~nm}$, which may be due increased grain sizes with snow depth. However, we feel the in-situ grain size measurements of snowpack using different wavelengths at the time of satellite pass can be more useful in this regard. Larger grain size and spatial variation in grain sizes were observed for the part of lower Himalaya due to high temperature conditions compared to middle Himalaya. Both the NIR wavelength bands can work well for flat and gradual sloping area but wavelength $1240 \mathrm{~nm}$ is more suitable in areas having steep slopes.

The narrowband spectral albedos contain important information on snow cover which can be used in many applications. To our knowledge no spectral albedo product is presently available on daily basis for Himalayan region where the albedo changes very fast due to seasonal variations. But the advantage of present discussed technique makes it suitable to retrieve spectral albedo on daily basis for Himalayan region. 
The operational quantitative snow retrieval maps can be generated fast using the above discussed methodology. However, for operational snow cover monitoring of Himalayan cryosphere, there is a need of good spectral, spatial, radiometric and temporal resolution space-borne sensors. With the new generation of satellite sensors like Sentinel-2 of ESA can be useful in this regard. The temporal retrieval of grain size and albedo estimation along gradual slope glaciers and basins can provide important input for Himalayan glacier and melt run-off studies (Painter et al., 2010).

Acknowledgements. The authors are thankful to Snow \& Avalanche Study Establishment (SASE), DRDO, India, to encourage this study and supporting by field observations. The authors are grateful to A. Ganju, SASE, India and J. B. Burrows, IUP, University of Bremen, Germany, for kind support. We thank to USGS for acquiring and providing Hyperion data. H. S. Negi acknowledges Department of Science and Technology (DST), India for providing BOYSCAST fellowship to this work. A. Kokhanovsky thanks ESA (Snow-Radiance Project) and JAXA (SGLI Cryosphere Project) for support of this research.

Edited by: A. Klein

\section{References}

Anderson, G. P., Pukall, B., Allred, C. L., Jeong, L. S., Hoke, M., Chetwynd, J. H., Adler-Golden, S. M., Berk, A., Bernstein, L. S., Richtsmeier, S. C., Acharya, P. K., and Matthew, M. W.: FLAASH and MODTRAN4: state-of-the-art atmospheric correction for hyperspectral data, Aerosp. Conf. Proc. IEEE, 4, 177181, doi:10.1109/AERO.1999.792088, 1999.

Bohren, C. F. and Barkstrom, B. R.: Theory of the optical properties of snow, J. Geophys. Res., 79(30), 4527-4535, 1974.

Bourdelles, B. and Fily, M.: Snow grain-size determination from Landsat imagery over Terre Adelie, Antarctica, Ann. Glaciol., 17, 86-92, 1993.

Brest, C. L. and Goward, S. N.: Deriving surface albedo measurements from narrow band satellite data, Int. J. Remote Sens., 8, 351-367, 1987.

Cooley, T., Anderson, G. P., Felde, G. W., Hoke, M. L., Ratkowski, A. J., Chetwynd, J. H., Gardner, J. A., Adler-Golden, S. M., Matthew, M. W., Berk, A., Bernstein, L. S., Acharya, P. K., Miller, D., and Lewis, P.: FLAASH, a MODTRAN4-based atmospheric correction algorithm, its application and validation, IGARSS, 3, 1414-1418, 2002.

Dozier, J.: Snow reflectance from LANDSAT-4 Thematic Mapper, IEEE T. Geosci. Remote, 22, 323-328, 1984.

Dozier, J.: Spectral signature of alpine snow cover from the Landsat Thematic Mapper, Remote Sens. Environ., 28, 9-22, 1989.

Dozier, J., Schneider, S. R., and McGinnis, Jr, D. F.: Effect of grain size and snow pack water equivalence on visible and nearinfrared satellite observations of snow, Water Resour. Res., 17, 1213-1221, 1981.

Dozier, J., Green, R. O., Nolin, A. W., and Painter T. H.: Interpretation of snow properties from imaging spectrometry, Remote Sens. Environ., 113, S25-37, 2009.
Fily, M., Bourdelles, B., Dedieu, J. P., and Sergent, C.: Comparison of In Situ and Landsat Thematic Mapper derived snow grain characteristics in the Alps, Remote Sens. Environ., 59, 452-460, 1997.

Greuell, W. and Oerlemans, J.: Narrowband-to-broadband albedo conversion for glacier ice and snow: equations based on modeling and ranges of validity of the equations, Remote Sens. Environ., 89, 95-105, 2004.

Gupta, R. P., Haritashya, U. K., and Singh, P.: Mapping dry/wet snow cover in the Indian Himalayas using IRS multispectral imagery, Remote Sens. Environ., 97, 458-469, 2005.

Hall, D. K., Riggs, G. A., and Salomonson, V. V.: Development of methods for mapping global snow cover using moderate resolution imaging spectroradiometer data, Remote Sens. Environ., 54, 127-140, 1995.

Hall D. K., Riggs G. A., Salomonson V. V., DiGirolamo, N. E., and Bayr, K. J.: MODIS snow cover products, Remote Sens. Environ., 83 181-194, 2002.

Immerzeel, W. W., Droogers, P., Jong, S. M., Bierkens, M. F. P.: Large-scale monitoring of snow cover and runoff simulation in Himalayan river basins using remote sensing, Remote Sens. Environ., 113, 40-49, 2009.

Jain, S. K., Goswami, A., and Saraf, A. K.: Accuracy assessment of MODIS, NOAA and IRS data in snow cover mapping under Himalayan conditions, Int. J. Remote Sens., 29, 5863-5878, 2008.

Jin, Z., Charlock, T. P., Yang, P., Xie, Y., and Miller, W.: Snow optical properties for different particle shapes with application to snow grain size retrieval and MODIS/CERES radiance comparison over Antarctica, Remote Sens. Environ., 112, 3563-3581, 2008.

Kasten, F.: Table of solar altitudes for geographical latitudes $\pm 77^{\circ} 10^{\prime}$; CRREL Special Report, 57 U.S. Army Corps of Engineers, Hanover, New Hampshire, 1962.

Kaufmann, Y. J., Wald, A. E., Remer, L. A., Gao, B. C., Li, R. R., and Flynn, L.: The MODIS 2.1-mm channel-correlation with visible reflectance for use in remote sensing of aerosol, IEEE T. Geosci. Remote, 35, 1286-1298, 1997.

Klein, A. G. and Stroeve, J.: Development and validation of a snow albedo algorithm for the MODIS instrument, Ann. Glaciol., 34, 45-52, 2002.

Klein, A. G., Hall, D. K., and Riggs, G. A.: Improving snow cover mapping in forests through the use of a canopy reflectance model, Hydrol. Process., 12, 1723-1744, 1998.

Kokhanovsky, A. A.: Polarization optics of random media, Springer, Dordrecht, UK, 2003.

Kokhanovsky, A. A.: Cloud optics, Springer-Praxis, Chichester, Netherlands, 2004a.

Kokhanovsky, A. A.: Spectral reflectance of whitecaps, J. Geophy. Res., 109, C05021, 15, doi:10.1029/2003JC002177, 2004b.

Kokhanovsky, A. and Schreier, M.: The determination of snow specific surface area, albedo and effective grain size using AATSR space-borne measurements, Int. J. Remote Sens., 30, 919-933, 2009.

Kokhanovsky, A. A. and Zege, E. P.: Scattering optics of snow, Appl. Opt., 43, 1589-1602, 2004.

Kokhanovsky, A. A. and Rozanov, V. V.: The retrieval of snow characteristics from optical measurements, Light Scattering Reviews 6, Springer-Praxis, Chichester, UK, 289-331, 2011 a.

Kokhanovsky, A. A., Aoki, T., Hachikubo, A., Hori, M., and Zege, 
E. P.: Reflective properties of natural snow: approximate asymptotic theory versus in situ measurements, IEEE T. Geosci. Remote, 43, 1529-1535, 2005.

Kokhanovsky, A., Mayer, B., von Hoyningen-Huene, W., Schmidt, S., and Pilewskie, P.: Retrieval of cloud spherical albedo from top-of-atmosphere reflectance measurements performed at a single observation angle, Atmos. Chem. Phys., 7, 3633-3637, doi:10.5194/acp-7-3633-2007, 2007.

Kokhanovsky, A. A., Rozanov, V. V., Aoki, T., Odermatt, D., Brockmann, B., Kruger, O., Bouvet, M., Drusch, M., and Hori, M.: Sizing snow grains using backscattered solar light, Int. J. Remote Sens., in press, $2011 \mathrm{~b}$.

Konig, M., Winther, J. G., and Isaksson E.: Measuring snow and glacier properties from satellite, Rev. Geophys., 39, 1-27, 2001.

Kulkarni, A. V., Singh, S. K., Mathur, P., and Mishra, V. D.: Algorithm to monitor snow cover using AWiFS data of RESOURCESAT-1 for the Himalayan region, Int. J. Remote Sens., 27, 2449-2457, 2006.

Kulkarni, A. V., Rathore, B. P., Singh, S. K., and Ajai: Distribution of seasonal snow cover in central and western Himalaya, Ann. Glaciol., 51, 123-128, 2010.

Kulkarni, A. V., Rathore, B. P., Singh, S. K., and Bahuguna, I. M.: Understanding changes in the Himalayan cryosphere using remote sensing techniques, Int. J. Remote Sens., 32, 601-615, 2011.

Li, W., Stamnes, K., Chen, B., and Xiong, X.: Snow grain size retrieved from near-infrared radiances at multiple wavelengths, Geophy. Res. Lett., 28, 1699-1702, 2001.

Liang, S.: Narrowband to broadband conversions of land surface albedo: I. Formulae, Remote Sens. Environ., 76, 213-238, 2000.

Liang, S., Fang, H., Chen, M., Shuey, C. J., Walthall, C., Daughtry, C., Morisette, J., Schaaf, C., and Strahler, A.: Validating MODIS land surface reflectance and albedo products: Methods and preliminary results, Remote Sens. Environ., 83, 149-162, 2002.

Lyapustin, A., Tedesco, M., Wang, Y., Aoki, T., Hori, M., and Kokhanovsky, A.: Retrieval of snow grain size over Greenland from MODIS, Remote Sens. Environ., 113, 1976-1987, 2009.

Mishchenko, M. I., Dlugach, J. M., Yanovitskij, E. G., and Zakharova, N. T.: Bidirectional reflectance of flat, optically thick particulate layers: an efficient radiative transfer solution and applications to snow and soil surfaces, J. Quant. Spectrosc. Ra., 63, 409-432, 1999.

Moody, E. G., King, M. D., Platnick, S., and Schaaf, C. B.: Spatially complete global spectral surface albedos: value-added datasets derived from Terra MODIS land products, IEEE Trans. Geosci. Remote Sens., 43, 144-158, 2005.

Negi, H. S. and Kokhanovsky, A.: Retrieval of snow albedo and grain size using reflectance measurements in Himalayan basin, The Cryosphere, 5, 203-217, doi:10.5194/tc-5-203-2011, 2011.

Negi, H. S., Kulkarni, A. V., and Semwal, B. S.: Estimation of snow cover distribution in Beas basin, Indian Himalaya using satellite data and ground measurements, J. Earth Sys. Sci., 118, 525-538, 2009a.

Negi, H. S., Kulkarni, A. V., and Semwal, B. S.: Study of contaminated and mixed objects snow reflectance in Indian Himalaya using spectroradiometer, Int. J. Remote Sens., 30, 315-325, $2009 \mathrm{~b}$.

Negi, H. S., Singh, S. K., Kulkarni, A. V., and Semwal, B. S.: Fieldbased spectral reflectance measurements of seasonal snow cover in the Indian Himalaya, Int. J. Remote Sens., 31, 2393-2417,
2010.

Nolin, A. W. and Dozier, J.: A hyperspectral method for remotely sensing the grain size of snow, Remote Sens. Environ., 74, 207 216, 2000.

Nolin, A. W. and Dozier, J.: Estimating snow grain size using AVIRIS data, Remote Sens. Environ., 44, 231-238, 1993.

Painter, T. H., Roberts, D. A., Green, R. O., and Dozier, J.: The effect of grain size on spectral mixture analysis of snow-covered area from AVIRIS Data, Remote Sens. Environ., 65, 320-332, 1998.

Painter, T. H., Dozier, J., Roberts, D. A., Davis, R. E., and Green, R. O.: Retrieval of subpixel snow-covered area and grain size from imaging spectrometer data, Remote Sens. Environ., 85, 64-77, 2003.

Painter, T. H., Rittger, K., McKenzie, C., Slaughter, P., Davis, R. E., and Dozier, J.: Retrieval of subpixel snow covered area, grain size, and albedo from MODIS, Remote Sens. Environ., 113, 868879, 2009.

Painter, T. H., Deems, J. S., Belnap, J., Hamlet, A. F., Landry, C. C., and Udall, B.: Response of Colorado River runoff to dust radiative forcing in snow, PNAS, 107, 17125-17130, 2010.

Riano, D., Chuvieco, E., Salas, J., and Aguado, I.: Assessment of different topographic corrections in Landsat TM data for mapping vegetation types, IEEE Trans. Geosci. Remote Sens., 41, 1056-1061, 2003.

Richter, R.: Atmospheric/Topographic correction for satellite imagery. Report DLR-IB 565-01/09, ftp://ftp.dfd.dlr.de/put/richter/ATCOR/, 2009.

Salomonson, V. V. and Appel, I.: Estimating fractional snow-cover from MODIS using the normalised difference snow index, Remote Sens. Environ., 89, 351-360, 2004.

Schaaf, C. B., Gao, F., Strahler, A. H., Lucht, W., Li, X. W., Tsang, T., Strugnell, N. C., Zhang, X. Y., Jin, Y. F., Muller, J. P., Lewis, P., Barnsley, M., Hobson, P., Disney, M., Roberts, G., Dunderdale, M., Doll, C., d'Entremont, R. P., Hu, B. X., Liang, S. L., Privette, J. L., and Roy, D.: First operational BRDF, albedo nadir reflectance products from MODIS, Remote Sens. Environ., 83, 135-148, 2002.

Sharma, S. S. and Ganju, A.: Complexities of avalanche forecasting in Western Himalaya - an overview, Cold Reg. Sci. Technol., 31, 95-102, 2000.

Smith, J. A., Tzeu, L. L., and Ranson, K. J.: The lambertian assumption and Landsat data, Phto. Engg. and Remote Sens., 46, 1183-1189, 1980.

Stamnes, K., Tsay, S. C., Wiscombe, W., and Jayaweera, K.: Numerically stable algorithm for discrete-ordinate-method radiative transfer in multiple scattering and emitting layered media, Appl. Opt., 27, 2502-2509, 1988.

Stamnes, K., Li, W., Eide, H., Aoki, T., Hori, M., and Storvold, R.: ADEOS-II/GLI snow/ice products - Part I: scientific basis, Remote Sens. Environ., 111, 258-273, 2007.

Stroeve, J., Box, J., Gao, F., Liang, S., Nolin, A., and Schaaf, C.: Accuracy assessment of the MODIS 16-day snow albedo product: Comparisons with Greenland in situ measurements, Remote Sens. Environ., 94, 46-60, 2005.

Stroeve, J. C., Box, J. E., and Haran, T.: Evaluation of the MODIS (MOD10A1) daily snow albedo product over the Greenland ice sheet, Remote Sens. Environ., 105, 155-171, 2006.

Tedesco, M. and Kokhanovsky, A. A.: The semi-analytical snow 
retrieval algorithm and its application to MODIS data, Remote Sens. Environ., 110, 317-331, 2007.

Teillet, P. M., Guindon, B., and Goodenough, D. G.: On the slope aspect correction of multispectral scanner data, Can. J. Remote Sens. 8, 84-106, 1982.

Vikhamar, D. and Solberg, R.: Snow-cover mapping in forests by constrained linear spectral unmixing of MODIS data, Remote Sens. Environ., 88, 309-323, 2003.

Wanner, W., Strahler, A. H., Hu, B., Lewis, P., Muller, J. P., Li, X., Schaaf, C. L. B., and Barnsley, M. J.: Global retrieval of bidirectional reflectance and albedo over land from EOS MODIS and MISR data: Theory and algorithm, J. Geophys. Res., 102, 17143-17161, 1997.

Warren, S. G.: Optical properties of snow, Rev. Geophys. Space Phy., 20, 67-89, 1982.
Warren, S. G. and Wiscombe, W. J.: A model for the spectral albedo of snow-II: snow containing atmospheric aerosols, J. Atmos. Sci., 37, 2734-2745, 1980.

Wiscombe, W. J. and Warren, S. G.: A model for the spectral albedo of snow-I: pure snow, J. Atmos. Sci., 37, 2712-2733, 1980.

Xie, Y., Ping, Y., Gao, B., Kattawar, G. W., and Mishchenko, M. I.: Effect of ice crystal shape and effective size on snow bidirectional reflectance, J. Quant. Spec. \& Rad. Trans., 100, 457-469, 2006.

Zege, E., Katsev, I., Malinka, A., Prikhach, A., and Polonsky, I.: New algorithm to retrieve the effective snow grain size and pollution amount from satellite data, Ann. Glaciol., 49, 139-144, 2008.

Zege, E. P., Katsev, I. L., Malinka, A. V., Prikhach, A. S., Heygster, G., and Wiebe, H.: Algorithm for retrieval of the effective snow grain size and pollution amount from satellite measurements, Remote Sens. Environ., 115, 2674-2685, 2011. 